\title{
Acidic or Alkaline? Towards a New Perspective on the Efficiency of Water Electrolysis
}

\author{
Maximilian Schalenbach,,${ }^{\mathrm{a}, \mathrm{c}, \mathrm{z}}$ Geert Tjarks, ${ }^{\mathrm{a}}$ Marcelo Carmo, ${ }^{\mathrm{a}}$ Wiebke Lueke, \\ Martin Mueller, ${ }^{a}$ and Detlef Stolten ${ }^{\mathrm{a}, \mathrm{b}}$ \\ ${ }^{a}$ Forschungszentrum Jülich GmbH, Institute of Energy and Climate Research, IEK-3: Electrochemical Process \\ Engineering, Jülich, Germany \\ ${ }^{b}$ Chair for Fuel Cells, RWTH Aachen University, Aachen, Germany
}

\begin{abstract}
Water electrolysis is a promising technology for enabling the storage of surplus electricity produced by intermittent renewable power sources in the form of hydrogen. At the core of this technology is the electrolyte, and whether this is acidic or alkaline affects the reaction mechanisms, gas purities and is of significant importance for the stability and activity of the electrocatalysts. This article presents a simple but precise physical model to describe the voltage-current characteristic, heat balance, gas crossover and cell efficiency of water electrolyzers. State-of-the-art water electrolysis cells with acidic and alkaline electrolyte are experimentally characterized in order to parameterize the model. A rigorous comparison shows that alkaline water electrolyzers with Ni-based catalysts but thinner separators than those typically used is expected be more efficient than acidic water electrolysis with Ir and Pt based catalysts. This performance difference was attributed mainly to a similar conductivity but approximately 38 -fold higher diffusivities of hydrogen and oxygen in the acidic polymer electrolyte membrane (Nafion) than those in the alkaline separator (Zirfon filled with a $30 \mathrm{wt} \% \mathrm{KOH}$ solution). With reference to the detailed analysis of the cell characteristics, perspectives for the improvement of the efficiency of water electrolyzers are discussed.

(C) The Author(s) 2016. Published by ECS. This is an open access article distributed under the terms of the Creative Commons Attribution 4.0 License (CC BY, http://creativecommons.org/licenses/by/4.0/), which permits unrestricted reuse of the work in any medium, provided the original work is properly cited. [DOI: 10.1149/2.0271611jes] All rights reserved.
\end{abstract}

Manuscript submitted May 23, 2016; revised manuscript received August 15, 2016. Published August 31, 2016. This paper is part of the JES Focus Issue on Electrolysis for Increased Renewable Energy Penetration.

In the endeavor to realize an environmentally-benign power supply infrastructure, water electrolysis for the production of hydrogen may prove a key technology for enabling energy conversion on a large scale. ${ }^{1,2}$ By applying a voltage to two electrodes immersed in an aqueous electrolyte, water can be electrochemically decomposed, evolving hydrogen at the negative pole, the cathode, and oxygen at the positive pole, the anode. During this process, protons or hydroxide ions must pass through the electrolyte to enable the electrochemical reactions at the electrodes. In order to achieve low extents of charge transport losses in electrolyzers, electrolytes with high conductivities are typically used. Such highly conductive electrolytes provide large quantities of ionic charge carriers (protons or hydroxide ions) and are thus either strong bases or acids. The reaction equations in acidic and alkaline aqueous regimes are displayed in Table I.

Besides liquid aqueous electrolytes in combination with porous separators, polymer electrolyte membranes (PEMs) are typically used as electrolytes for water electrolysis and to separate the hydrogen and oxygen produced during operation. ${ }^{3}$ In PEMs, ionizable functional groups are embedded within a polymer matrix providing either mobile protons or hydroxide ions. ${ }^{4}$ In an aqueous phase that is separated from the solid polymeric phase ${ }^{5,6}$ the protons or hydroxide ions are dissolved but attracted to the oppositely charged ions of the functional group which are covalently bonded to the polymer matrix. As a result, the dissolved ions are captured inside the aqueous phase of the PEM. ${ }^{7}$ Hence, an advantage of solid PEMs is that pure water can supplied to the cell, which means that only the components that are in direct contact with the PEM are exposed to its corrosive alkaline or acidic aqueous phase.

The utility of alkaline PEMs (also known as anion exchange membranes) is limited by their durability during water electrolysis (the best reported lifetime in the literature was $1,000 \mathrm{~h}^{8}$ ), whereas the more stable acidic PEMs are expected to operate for up to $100,000 \mathrm{~h}$ in water electrolyzers. ${ }^{9}$ Accordingly, low-temperature water elec-

${ }^{c}$ Present address: Department of Interface Chemistry and Surface Engineering, MaxPlanck-Institut für Eisenforschung, Düsseldorf, Germany.

E-mail: m.schalenbach@mpie.de trolysis is typically conducted with either acidic $\mathrm{PEMs}^{3}$ or liquid lyes. ${ }^{10}$ In the latter case, a porous separator (also commonly referred to as diaphragm) divides the anodic and cathodic compartments. ${ }^{11}$ The transition metals from the $8^{\text {th }}$ to $10^{\text {th }}$ row of the periodic table are the most suitable metals for the active components of water electrolyzer catalysts, ${ }^{12-14}$ which can be attributed to their $d$ band character. ${ }^{15,16}$ The abundant lower transition metals of the iron group (iron, cobalt, and nickel) are stable in the alkaline regime, ${ }^{17-19}$ while in the acidic regime, only those of the platinum group show sufficient stability against corrosion in order to enable long-term operation. ${ }^{19-21}$

By means of a simple physical model which is presented in this study, a scientific comparison of the cell efficiencies of alkaline and acidic water electrolyzers is enabled. In the following, first the physical model is presented. Second, measured characteristics of state-of-theart electrolysis cells are discussed and used to parameterize the model. Third, the cell efficiencies of both electrolyzers are modeled and their perspectives are elucidated.

\section{Modeling Electrolyzer Efficiency}

In this section, the physical model to describe the cell efficiency of water electrolyzers is presented. The model consists of analytical equations which can be calculated with commonly used computer programs such as Excel, OriginLab, MATLAB, etc. Figure 1 illustrates the influences of the operation parameters and cell properties on the cell characteristics that are described by the model. In order to describe the cell characteristics independent of the cell geometry, the current is typically normalized to the cell area, leading to the current density $j$, while the resistances are also normalized to cell area as described by 'area resistances' in the units of $\Omega \mathrm{cm}^{2}$.

Description of the cell efficiency.-The most general definition of the efficiency of water electrolysis $\eta$ is given by the chemical energy that contains a produced amount of hydrogen to the energy that is spend to produce this amount. In steady states, this ratio equals the power $P_{\text {ideal }}$ that is thermodynamically required for a certain hydrogen production rate divided by the electrical power $P_{\text {real }}$ 
Table I. Reaction equations of water electrolysis in the acidic and alkaline regime.

\begin{tabular}{ccc} 
& Acid & Alkaline \\
\hline Anode & $2 \mathrm{H}_{2} \mathrm{O} \rightarrow 4 \mathrm{H}^{+}+\mathrm{O}_{2}+4 \mathrm{e}^{-}$ & $4 \mathrm{OH}^{-} \rightarrow \mathrm{O}_{2}+2 \mathrm{H}_{2} \mathrm{O}+4 \mathrm{e}^{-}$ \\
Cathode & $2 \mathrm{H}^{+}+2 \mathrm{e}^{-} \rightarrow \mathrm{H}_{2}$ & $2 \mathrm{H}_{2} \mathrm{O}+2 \mathrm{e}^{-} \rightarrow 2 \mathrm{OH}^{-}+\mathrm{H}_{2}$
\end{tabular}

for it expended:

$$
\eta=\frac{P_{\text {ideal }}}{P_{\text {real }}}
$$

The efficiency aspects discussed in this study concern the efficiency of water electrolysis cells, where the energy consumption of system components such as water pumps and power electronics are not included. On the cell level, the power expended equals the product of the applied voltage $U_{\text {cell }}$ and the resulting cell current $I$ plus the power consumed for the heat balance of the cell. The efficiency on the cell level will be denoted as $\eta_{\text {cell }}$. The thermodynamic power required for the hydrogen production equals the thermodynamic reference voltage $U_{\text {ref }}$ times the current that contributes to the hydrogen output of the water electrolyzer. As thermodynamic reference voltages for the electrochemical water decomposition, typically either the reversible voltage $U_{\text {rev }}$ (corresponding to Gibbs free energy or lower heating value) of $1.23 \mathrm{~V}$ or the thermoneutral voltage $U_{\text {tn }}$ (corresponding to the enthalpy or higher heating value) of $1.48 \mathrm{~V}$ at standard ambient temperature and pressure are used. The thermoneutral voltage takes the irreversible heat of evaporation for the phase transition of liquid water to the gaseous hydrogen and oxygen into account, which is not included by the reversible voltage. At cell voltages below the thermoneutral voltage water electrolysis is an endothermic process, while higher voltages mean an exothermic process.

The current loss $I_{\text {loss }}$ is defined here as the amount of current applied which does not result in viable cathodic hydrogen output of the cell. This current loss is mainly attributable to the hydrogen and oxygen cross-permeation through the separator (as further discussed in the Gas crossover section). Accordingly, the difference between the total current $I$ applied and current loss $I_{\text {loss }}$ is equal to the current that achieves a viable hydrogen output. By employing the presented definitions, the latter equation can be rewritten as

$$
\eta_{\text {cell }}=\frac{U_{\text {ref }}\left(I-I_{\text {loss }}\right)}{U_{\text {cell }} I}
$$

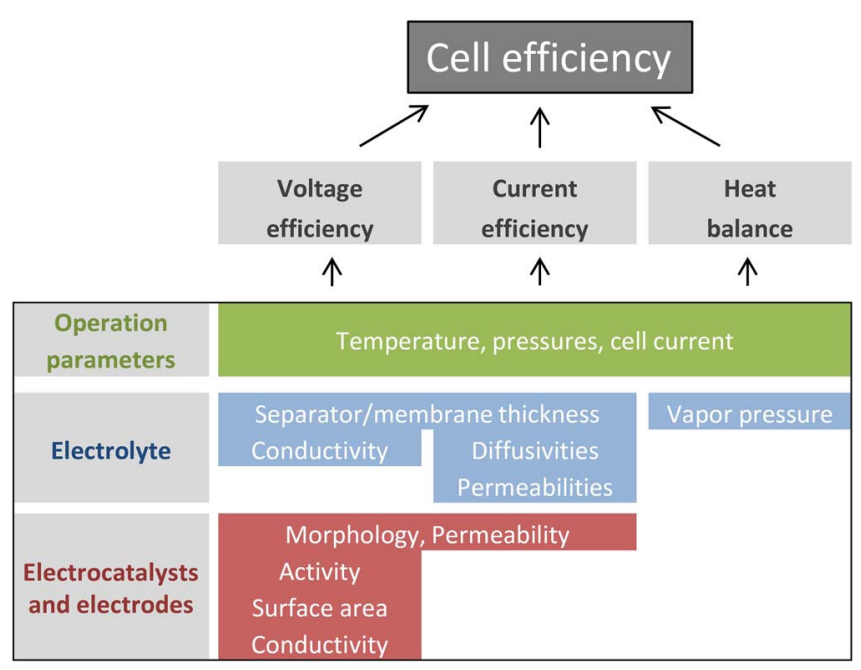

Figure 1. Schema representing the modeled influence of the operation parameters and the properties of the electrolyte, electrocatalysts and electrodes on the voltage efficiency, current efficiency, heat balance and cell efficiency. and transposed to

$$
\eta_{\text {cell }}=\underbrace{\left(\frac{U_{\text {ref }}}{U_{\text {cell }}}\right)}_{\eta_{U}} \times \underbrace{\left(1-\frac{I_{\text {loss }}}{I}\right)}_{\eta_{C}},
$$

where $\eta_{U}$ is defined as the voltage efficiency and $\eta_{C}$ as the current efficiency (also commonly referred to as faradaic efficiency).

Pressure increase by gas evolution.-The hydrogen and oxygen produced during water electrolysis are typically saturated with water vapor. ${ }^{22}$ During their evolution their partial pressures in the electrodes increases, respectively, which is a consequence of mass transport and supersaturation $^{23,24}$ by their electrolytic production. A detailed description of these phenomena are given in the supporting information (SI) to this article provided online. In short, the molar gas flux (Faraday's law) from the inside of an electrode to the cell outlet is proportional to the current density, while the pressure drop of the gas permeation (described by Darcy's law and Fick's law) is proportional to this flux. Thus, a linear relation between pressure inside the electrode and the current density results, that is here described by proportionality constant $\Upsilon$. Accordingly, the partial hydrogen pressure in the cathode $p_{\mathrm{H}_{2}}^{\mathrm{c}}$ is derived to increase proportional to the the current density $j$

$$
p_{\mathrm{H}_{2}}^{\mathrm{c}}=p^{\mathrm{c}}+\Upsilon_{\mathrm{H}_{2}} j-p_{\mathrm{sv}}(T),
$$

where $p^{c}$ denotes the applied absolute pressure at the cathodic gas outlet, $\Upsilon_{\mathrm{H}_{2}}$ the cathodic partial pressure increase factor and $p_{\mathrm{sv}}(T)$ the saturated vapor pressure (calculated by the data of the NIST database ${ }^{25}$ for water and the data reported by Balej et al. ${ }^{26}$ for $\mathrm{KOH}$ solutions). In the SI, the transport of gases from the inside of the electrode to the cell outlet is derived to by dominated by the driving force of differential pressure while diffusion plays a minor role. The partial pressure of oxygen at the anode $p_{\mathrm{O}_{2}}^{\mathrm{a}}$ during the oxygen evolution at the anode is described analogously by a linear dependence on the current density $j$, while in this case $\Upsilon_{\mathrm{O}_{2}}$ describes the anodic partial pressure increase factor.

Voltage-current characteristic.-The reversible cell voltage as a function of the temperature $T, p_{\mathrm{H}_{2}}^{\mathrm{c}}$ and $p_{\mathrm{O}_{2}}^{\mathrm{a}}$ is commonly denoted as the Nernst voltage $U_{\mathrm{N}}$

$$
U_{\mathrm{N}}=U_{\mathrm{rev}}+\frac{\mathrm{R} T}{2 \mathrm{~F}} \ln \left(\frac{p_{\mathrm{H}_{2}}^{\mathrm{c}} \sqrt{p_{\mathrm{O}_{2}}^{\mathrm{a}}}}{p_{0}^{3 / 2} a_{\mathrm{H}_{2} \mathrm{O}}}\right),
$$

where $p_{0}$ denotes the standard ambient pressure ${ }^{27}$ and $a_{\mathrm{H}_{2} \mathrm{O}}$ the activity of water. When liquid water is present at the electrodes, $a_{\mathrm{H}_{2} \mathrm{O}}$ equals unity. To describe the temperature dependence of the reversible cell voltage, the linear approximation

$$
U_{\mathrm{rev}} \approx 1.229 \mathrm{~V}-0.000846 \mathrm{VK}^{-1}(T-298.15 \mathrm{~K})
$$

can be used. ${ }^{28}$

The relation of the applied voltage $U_{\text {cell }}$ and the resulting current density $j$ equals the sum of the Nernst voltage $U_{\mathrm{N}}$, the kinetic overpotential $U_{\text {kin }}$, the Ohmic drop caused by electron and ion conduction $U_{\Omega}$, and overvoltages $U_{\mathrm{rs}}$ caused by reactant starvation:

$$
\begin{aligned}
U_{\text {cell }}\left(p_{\mathrm{H}_{2}}^{\mathrm{c}}, p_{\mathrm{O}_{2}}^{\mathrm{a}}, j, T\right)= & U_{\mathrm{N}}\left(p_{\mathrm{H}_{2}}^{\mathrm{c}}, p_{\mathrm{O}_{2}}^{\mathrm{a}}, j, T\right)+U_{\Omega}(j, T) \\
& +U_{\mathrm{kin}}(j, T)+U_{\mathrm{rs}}(j, T)
\end{aligned}
$$

When more water is electrochemically oxidized at the anodic catalyst (acidic electrolyzer) or reduced at the cathode (alkaline electrolyzer) than transported to the catalyst, the amount of liquid water at the respective catalyst decreases. Accordingly, the activity of water $a_{\mathrm{H}_{2} \mathrm{O}}$ at the catalyst decreases and an thus increase of the Nernst voltage (Eq 5) results. In this case an exponential-like influence on the cell voltage as a function of the cell current results, ${ }^{27}$ which is described by the above introduced parameter $U_{\mathrm{rs}}$. However, such an exponential 
increase of the voltage with the current density could not be observed, which means that this effect can be estimated to have a negligible impact on the examined electrolyzers in this study. Thus, here this effect is not considered in detail.

In this study, the Ohmic drop is divided into the contributions originating from the area resistance $R_{\text {sep }}$ of ion conduction through the separator and the area resistance $R_{\mathrm{e}}$ arising from other sources. As derived in the Resistances section, the main contributions to $R_{\mathrm{e}}$ are attributable to the ion conduction through the electrodes and contact resistances. Accordingly, $R_{\mathrm{e}}$ is denoted as the electrode resistance. By employing the definitions stated above, the sum of $R_{\text {sep }}$ and $R_{\mathrm{e}}$ equals the total area resistance $R_{\mathrm{t}}$, so that the Ohmic drop at the cell can be calculated to:

$$
U_{\Omega}=R_{\mathrm{t}} j=\left(R_{\mathrm{e}}+R_{\mathrm{sep}}\right) j
$$

The area resistance of the separator is related by

$$
R_{\text {sep }}=\frac{d}{\kappa_{\text {sep }}}
$$

to its conductivity $\kappa_{\text {sep }}$ and its thickness $d$, which corresponds (in a zero gap configuration that is discussed in the Experimental section) to the distance between the electrodes.

In acidic PEMs, the dissolved protons of the functional groups are moveable, while the anions are fixed by their covalent bonding to the polymer matrix. ${ }^{29}$ When all the cations of the functional group are protons, equal direct current (DC) and alternating current (AC) resistances result. ${ }^{29}$ In contrast, in the case of a liquid electrolyte such as potassium hydroxide $(\mathrm{KOH})$, anions and cations can move. Thus, using current interrupt or impedance measurements, both, anions and cations contribute to the measured conductivity of liquid electrolytes. However, stationary currents during water electrolysis mean that only protons or hydroxide ions can contribute to the conductivity (as these are the only ions that are involved in the reactions and thus exchanged between the electrodes). Typically charge transfer coefficients are used to describe the contributions of the different ions to the overall conductivity. In the case of the $\mathrm{KOH}$ solutions, the charge transfer coefficient of hydroxide ions $t_{\mathrm{OH}^{-}}$relates the conductivity by hydroxide ions $\kappa_{\mathrm{OH}^{-}}$to that of the overall conductivity $\kappa_{\mathrm{KOH}}$ :

$$
\kappa_{\mathrm{OH}^{-}}=\kappa_{\mathrm{KOH}} t_{\mathrm{OH}^{-}}
$$

A detailed estimation of $t_{\mathrm{OH}^{-}}$for $\mathrm{KOH}$ is discussed in the SI. By impedance spectroscopy, the area resistance of electrolysis cells is typically measured at high frequencies (as discussed in the SI) and is here defined as $R_{\mathrm{hf}}$. The area resistances $R_{\mathrm{t}}, R_{\text {sep }}$ and $R_{\mathrm{e}}$ refer to DCs during water electrolysis while $R_{\mathrm{hf}}$ refers to ACs that are applied during impedance spectroscopy.

The kinetic overvoltage of both, the anodic and cathodic reaction are in this study described by the Tafel equation (that was derived from the Butler-Volmer relation as discussed in the SI) to

$$
U_{\text {kin }} \approx a \ln \left(j / j_{0}\right),
$$

where $j_{0}$ (the exchange current density normalized to the cell area) and $a$ (the Tafel slope) denote kinetic parameters. Summarizing the equations stated above, the voltage-current characteristics (with neglected contributions of the reactant starvation) of the water electrolysis cells in this study are described by:

$$
\begin{aligned}
U_{\text {cell }}= & 1.229 \mathrm{~V}-0.000846 \mathrm{VK}^{-1}(T-298.15 \mathrm{~K}) \\
& +\frac{\mathrm{R} T}{2 \mathrm{~F}} \ln \left(\frac{\left(p^{\mathrm{c}}+\Upsilon_{\mathrm{H}_{2}} j-p_{\mathrm{sv}}\right) \sqrt{p^{\mathrm{a}}+\Upsilon_{\mathrm{O}_{2}} j-p_{\mathrm{sv}}}}{p_{0}^{3 / 2}}\right) \\
& +\left(R_{\mathrm{e}}+R_{\mathrm{sep}}\right) j+a \ln \left(j / j_{0}\right)
\end{aligned}
$$

Heat balance.-The phase transition by the decomposition of liquid water to gaseous hydrogen and oxygen involves an increase of entropy, which must be spend in terms of the enthalpy of vaporization. In addition, enthalpy of vaporization is consumed by water vapor in the produced gases. The enthalpy of vaporization consumes heat and thus can reduce the cell temperature. Heat dissipation by convection and radiation to the environment further reduce the cell temperature. ${ }^{22}$ In contrast to these factors that decrease the cell temperature, heat is produced by the Ohmic and kinetic overvoltages.

Leroy et al. ${ }^{22}$ defined the applied cell voltage, at which the cell temperature of a water electrolyzer is constant without an active heat management as the thermobalanced voltage $U_{\mathrm{tb}}$. The cell temperature is reduced by smaller cell voltages than the thermobalanced voltage whereas it is increased by higher voltages. ${ }^{22}$ LeRoy et al. ${ }^{22}$ proposed an equation to calculate the influence of water vapor in the product gases on the thermobalanced voltage. This equation is only valid for balanced pressure operation and is in the following adopted to differential pressures. The thermobalanced voltage defined by LeRoy et al. ${ }^{22}$ takes into account the reversible voltage $U_{\text {rev }}$, the heat of vaporization $T \Delta S$ caused by the phase transition of liquid water to gaseous hydrogen and oxygen, the heat of vaporization $H_{\mathrm{ev}}^{\mathrm{gas}}$ spend for water vapor in the product gases, the energy $E_{\text {supply }}$ required to increase the temperature of the water supply to that of the cell, and heat dissipation into the environment. In this study, thermal insulation is assumed to reduce heat dissipation by radiation and convection into the environment to a negligible amount. Accordingly, the thermobalanced voltage is described by:

$$
U_{\mathrm{tb}}=U_{\text {rev }}+\frac{T \Delta S}{2 \mathrm{~F}}+\frac{E_{\text {supply }}}{2 \mathrm{~F}}+\frac{H_{\mathrm{ev}}^{\mathrm{gas}}}{2 \mathrm{~F}}
$$

The energy required to heat up the consumed water in the cell from the supply temperature (assumed as $20^{\circ} \mathrm{C}$ ) to the cell temperature $\left(80^{\circ} \mathrm{C}\right)$ can be calculated to approximately $E_{\text {supply }} \approx 4.5 \mathrm{~kJ} \mathrm{~mol}^{-1}$, which corresponds to a voltage of approximately $23 \mathrm{mV}$. Based on the mole fraction of the water vapor in the product gases, $H_{\mathrm{ev}}^{\text {gas }}$ can be derived to:

$$
H_{\mathrm{ev}}^{\mathrm{gas}}=T \Delta S\left(\frac{p_{\mathrm{sv}}}{p^{\mathrm{c}}}+0.5 \frac{p_{\mathrm{sv}}}{p^{\mathrm{a}}}\right)
$$

The heat of vaporization $T \Delta S$ was calculated via the Gibbs-Helmholtz equation $(T \Delta S=\Delta H-\Delta G)$ and a linear interpolation of the values of $\Delta G$ and $\Delta H$ for $80^{\circ} \mathrm{C}$ reported by Barin et al. ${ }^{30}$ to a voltage equivalent of $0.315 \mathrm{~V}$.

When a constant cell temperature is desired, the influence of the load on the cell temperature can be balanced by heating or cooling, which is described by model as follows: (i) In the case of $U_{\text {cell }}>U_{\mathrm{tb}}$, cooling of the cell is assumed to be realized without large energy consumption by the rate that either water (PEM electrolyzer) or the alkaline electrolyte (alkaline electrolyzer) is pumped through cell. These circulating liquids can carry the heat from the cell to the environment. (ii) In the case of $U_{\text {cell }}<U_{\mathrm{tb}}$, the heat power $P_{\text {heat }}=\left(U_{\mathrm{tb}}-U_{\text {cell }}\right) \times I_{\text {cell }}$ has to be put into the cell in order to maintain the cell temperature. On the basis of these two different cases, the voltage efficiency including the power consumption of the heat balance (denoted as $\tilde{\eta}_{U}$ ) is described by:

$$
\begin{gathered}
\tilde{\eta}_{\mathrm{U}}=\frac{U_{\text {ref }}}{U_{\mathrm{tb}}} \quad \text { for } \quad U_{\text {cell }} \leq U_{\mathrm{tb}} \\
\tilde{\eta}_{\mathrm{U}}=\frac{U_{\text {ref }}}{U_{\text {cell }}} \text { for } \quad U_{\text {cell }}>U_{\mathrm{tb}}
\end{gathered}
$$

The overall cell efficiency including the heating of the cell is calculated by

$$
\tilde{\eta}_{\text {cell }}=\tilde{\eta}_{\mathrm{U}} \eta_{\mathrm{c}}
$$

In the following, $\tilde{\eta}_{\text {cell }}$ normalized to $U_{\text {ref }}=1.48 \mathrm{~V}$ (the higher heating value) is denoted as $\tilde{\eta}_{\mathrm{HHV}}$, while its normalization to $U_{\text {ref }}=1.23 \mathrm{~V}$ (the lower heating value) is denoted as $\tilde{\eta}_{\text {LHV }}$.

Gas crossover.-The permeation of cathodic hydrogen to the anode leads to a direct loss of the produced hydrogen and thus reduces the efficiency. Anodic hydrogen is typically not oxidized at the oxidecovered anodic catalyst ${ }^{31,32}$ and thus mixes with the oxygen produced 
at the anode. The anodic gas mixture is typically released into the environment. Oxygen that comes from the anode to the non-oxide covered cathodic catalyst can be catalytically or electrochemically recombined with hydrogen to form water. Alternatively, anodic oxygen can crosspermeate to the cathodic gas outlet and thus affect the hydrogen purity. In order to remove the oxygen impurities of the hydrogen produced, both gases can be catalytically recombined at a catalyst. In this case, cross-permeated oxygen consumes twice the molar amount of hydrogen (stoichiometric composition of $\mathrm{H}_{2} \mathrm{O}$ ). Besides the gas crossover, parasitic currents through the electrolyte or water supply between cells that are connected in series (commonly referred to as stack of cells) can contribute to the current loss. These parasitic currents can be minimized to a negligible amount by the design of the electrolyzer ${ }^{33}$ and thus will not be considered in this study. At constant DC currents, the conversion efficiency of the hydrogen and oxygen evolution reactions are at proper catalysts typically $100 \% .{ }^{20}$ Concluding, the current efficiency is primarily affected by the cross-permeation of hydrogen and oxygen through the separator. ${ }^{31}$

Using Faraday's law, the current density between the electrodes during water electrolysis can be related to the molar production rate density $\Gamma$ of hydrogen or oxygen by

$$
\Gamma=\frac{j}{z \mathrm{~F}}
$$

where $z$ denotes the number of electrons involved in the half reactions (two for hydrogen and four for oxygen). On the basis of Faraday's law, the current loss $I_{\text {loss }}$ normalized to the cell area can be derived to

$$
j_{\text {loss }}=2 \mathrm{~F} \Phi_{\mathrm{H}_{2}}+4 \mathrm{~F} \Phi_{\mathrm{O}_{2}},
$$

where $\Phi_{\mathrm{H}_{2}}$ and $\Phi_{\mathrm{O}_{2}}$ denote the molar hydrogen and oxygen permeation flux densities through the separator or membrane. The latter equation describes a two times larger impact of the molar oxygen cross-permeation flux density on the current loss than that of hydrogen (based on the discussion above). By combining the latter equation, the definition of the current efficiency (Eq 3) and Equation 18, the equation to determine the current efficiency can be derived to:

$$
\eta_{\mathrm{C}}=1-\frac{\Phi_{\mathrm{H}_{2}}}{\Gamma_{\mathrm{H}_{2}}}-2 \frac{\Phi_{\mathrm{O}_{2}}}{\Gamma_{\mathrm{H}_{2}}}
$$

The anodic hydrogen content $A H C$ is equal to the molar percentage of cross-permeated hydrogen in the oxygen that is evolved at the anode and can be used as a measure for the hydrogen cross-permeation flux:

$$
A H C=\frac{\Phi_{\mathrm{H}_{2}}}{\Gamma_{\mathrm{O}_{2}}+\Phi_{\mathrm{H}_{2}}} \times 100 \mathrm{~mol} \%
$$

Diffusion (which is driven by concentration differences of the dissolved gases between the anode and cathode, respectively) displays one of the driving forces for the gas cross-permeation. The hydrogen cross-permeation flux density (denoted as $\Phi_{\mathrm{H}_{2}}^{\text {Fick }}$ ) driven by the diffusion can be derived on the basis of Fick's law (as discussed in the SI in detail) to

$$
\Phi_{\mathrm{H}_{2}}^{\text {Fick }}=-\underbrace{D_{\mathrm{H}_{2}} S_{\mathrm{H}_{2}}}_{\varepsilon_{\mathrm{H}_{2}}^{\text {Fick }}} \frac{\Delta p_{\mathrm{H}_{2}}}{d},
$$

where $D_{\mathrm{H}_{2}}$ denotes the diffusion coefficient of hydrogen in the separator, $S_{\mathrm{H}_{2}}$ its hydrogen solubility, $\varepsilon_{\mathrm{H}_{2}}^{\text {Fick }}$ its diffusivity (or Fickian hydrogen permeability) and $\Delta p_{\mathrm{H}_{2}}$ the partial pressure difference of hydrogen at the anode and cathode. In the case of $p_{\mathrm{H}_{2}}^{\mathrm{c}} \gg p_{\mathrm{H}_{2}}^{\mathrm{a}}$, the approximation $\Delta p_{\mathrm{H}_{2}} \approx-p_{\mathrm{H}_{2}}^{\mathrm{c}}$ can be set into the latter equation. The exact solution of this equation is discussed in the SI. The expression to describe the molar oxygen cross-permeation flux density caused by the diffusion (described by $\Phi_{\mathrm{O}_{2}}^{\text {Fick }}$ ) can be derived analogously.

Besides diffusion, cross-permeating electrolyte driven by differential pressures $\Delta p$ between the anodic and cathodic compartment can carry dissolved gases. ${ }^{34}$ Based on Darcy's law, the hydrogen crosspermeation flux by convection for higher cathodic than anodic absolute pressures can be derived (as discussed in the SI in detail) to ${ }^{34}$

$$
\Phi_{\mathrm{H}_{2}}^{\text {Darcy }}=-\underbrace{\frac{K}{\mu} S_{\mathrm{H}_{2}} p_{\mathrm{H}_{2}}^{\mathrm{c}}}_{\varepsilon_{\text {Darcy }}^{\mathrm{H}_{2}}} \frac{\Delta p}{d},
$$

where $\Phi_{\mathrm{H}_{2}}^{\text {Darcy }}$ denotes the hydrogen cross-permeation flux density driven by differential pressures, $K$ the electrolyte permeability and $\mu$ the viscosity of the liquid electrolyte. In the latter equation, the hydrogen permeability driven by $\Delta p$ is defined as $\varepsilon_{\mathrm{H}_{2}}^{\text {Darcy }}$. Although differential pressure is the driving force for this permeation mechanism, the partial hydrogen pressure at the cathode affects $\Phi_{\mathrm{H}_{2}}^{\text {Darcy }}$, as it is responsible for the hydrogen concentration in the electrolyte (according to Henry's law). The expression to describe the oxygen cross-permeation flux density can be derived analogously and is valid if the absolute anodic pressure is higher than that at the cathode.

In addition to diffusion and differential pressure driven crosspermeation of the produced gases, the migration of ions between the electrodes and a resulting convection can be a driving force for the gas crossover. In the SI, this interaction is physically described. However, in the Gas purities section the impact of the ion migration on the hydrogen crossover is estimated to be negligible, for which reason this interaction is not considered here in detail.

In the case of $\Phi_{\mathrm{H}_{2}}^{\text {Fick }} \gg \Phi_{\mathrm{H}_{2}}^{\text {Darcy }}$, the overall hydrogen crosspermeation flux density can be approximated as $\Phi_{\mathrm{H}_{2}} \approx \Phi_{\mathrm{H}_{2}}^{\text {Fick }}$. Using this relation and the approximation $\Delta p_{\mathrm{H}_{2}} \approx-p_{\mathrm{H}_{2}}^{\mathrm{c}}$, the anodic hydrogen content of an electrolysis cell can be derived on the basis of Equations 21, 22 and 4 to:

$$
A H C \approx\left(\frac{j d}{4 \mathrm{~F}_{\mathrm{H}_{2}}^{\text {Fick }}\left(p^{\mathrm{c}}+\Upsilon_{\mathrm{H}_{2}} j-p_{\mathrm{sv}}\right)}+1\right)^{-1} \times 100 \mathrm{~mol} \%
$$

Using the same approximations, the current efficiency can be calculated on the basis of Equations 20 and 22 by:

$$
\eta_{\mathrm{C}}=1-\frac{2 \mathrm{~F}}{j d}\left(\varepsilon_{\mathrm{H}_{2}}^{\mathrm{Fick}}\left(p^{\mathrm{c}}+\Upsilon_{\mathrm{H}_{2}} j-p_{\mathrm{sv}}\right)+2 \varepsilon_{\mathrm{O}_{2}}^{\mathrm{Fick}}\left(p^{\mathrm{a}}+\Upsilon_{\mathrm{O}_{2}} j-p_{\mathrm{sv}}\right)\right)
$$

In the case of $\Phi_{\mathrm{H}_{2}}^{\text {Darcy }} \gg \Phi_{\mathrm{H}_{2}}^{\text {Fick }}$, the overall hydrogen cross-permeation flux density can be approximated as $\Phi_{\mathrm{H}_{2}} \approx \Phi_{\mathrm{H}_{2}}^{\text {Darcy }}$. With this relation and $p^{\mathrm{c}}>p^{\mathrm{a}}$, the equation to calculate the anodic hydrogen content can be derived on the basis of Equations 21, 23 and 4 to:

$$
A H C \approx\left(\frac{j d}{4 \mathrm{~F}_{\mathrm{H}_{2}}^{\text {Darcy }}\left(p^{\mathrm{c}}-p^{\mathrm{a}}+j\left(\Upsilon_{\mathrm{H}_{2}}-\Upsilon_{\mathrm{O}_{2}}\right)\right)}+1\right)^{-1} \times 100 \mathrm{~mol} \%
$$

Using the approximations stated for this case, the current efficiency can be described on the basis of Equations 20 and 23 by:

$$
\eta_{\mathrm{C}}=1-\frac{2 \mathrm{~F}}{j d}\left(\left(p^{\mathrm{c}}-p^{\mathrm{a}}\right) \varepsilon_{\mathrm{H}_{2}}^{\text {Darcy }}\right)
$$

When $\Delta p$ shows the opposing sign $\left(p^{\mathrm{a}}>p^{\mathrm{c}}\right)$, the differential pressure pushes oxygen from the anode to the cathode while the hydrogen permeation from the cathode to the anode is negligible. The latter equation can be adopted to this case by replacing $p^{\mathrm{c}}-p^{\mathrm{a}}$ by $p^{\mathrm{a}}-p^{\mathrm{c}}$ and $\varepsilon_{\mathrm{H}_{2}}^{\text {Darcy }}$ by $\varepsilon_{\mathrm{O}_{2}}^{\text {Darcy }}$.

Calculation of the cell efficiency.-In the previous sections, all the equations to model the cell efficiency were presented. To summarize, the voltage efficiency including the heat balance can be determined using Equations 15, 16 and 12. The equation to model the current efficiency is given either by 27 or 26 , depending if diffusion or differential pressure is the dominating driving force for the gas crosspermeation. Finally, the cell efficiency including the heat balance (as 
the product of the voltage and current efficiency) can be calculated by Equation 17.

\section{Experimental}

The water electrolyzer cells characterized in this study were build in-house and are designed similar to those that showed the best performance in the literature. ${ }^{35,36}$ A detailed description of the experimental setup, experimental characterization techniques and a performance comparison of the constructed cells to reported data in the literature is provided in the SI. All measurements were conducted at cell temperatures of $80^{\circ} \mathrm{C}$, while the stated pressures refer to absolute pressures.

Alkaline water electrolyzer.-The electrodes of the alkaline water electrolyzer consisted of $340 \mu \mathrm{m}$ thick perforated Nickel plates with holes of $1.6 \mathrm{~mm}$ diameter and a mean open area of approximately $66 \%$. These plates were coated by vacuum plasma spraying ${ }^{37}$ with gas atomized alloy powders of particle sizes below $40 \mu \mathrm{m}$ (H.C. Starck, Germany). Powders containing $39 \mathrm{wt} \% \mathrm{Ni}, 44 \mathrm{wt} \% \mathrm{Al}$, and $17 \mathrm{wt} \%$ Mo were applied to the cathode, while $56 \mathrm{wt} \% \mathrm{Ni}$ and $44 \mathrm{wt} \% \mathrm{Al}$ were employed for the anode. The detailed parameters of the spraying procedure are given in the SI. The layer thickness of the coatings ranged from $110 \mu \mathrm{m}$ to $130 \mu \mathrm{m}$. The aluminum of the coatings was leached in alkaline solution yielding nanoporous Raney-Nickel structures. ${ }^{38} \mathrm{~A}$ commercially available Zirfon Perl UTP-500 (Agfa) ${ }^{39}$ separator with a thickness of approximately $460 \mu \mathrm{m}$ separated the electrodes. In the cell assembly, the electrodes were pressed onto the diaphragm (zero gap configuration ${ }^{10,40}$ ). During the operation, an aqueous solution of $30 \mathrm{wt} \%$ potassium hydroxide electrolyte (corresponding to a concentration of $6.9 \mathrm{M}^{41}$ ) was purged along the electrodes through the cell in individual circulation loops for the anode and cathode, respectively.

Acidic PEM water electrolyzer.-The electrolyte of the acidic water electrolyzer consisted of a Nafion N117 membrane (a thickness of approximately $209 \mu \mathrm{m}$ in the wet state) $)^{42}$ and Nafion ionomer based electrodes. Platinum nanoparticles supported on carbon (Johnson Matthey, HiSpec $9100^{43}$ ) with a Pt loading of $0.1 \mathrm{mg} \mathrm{cm}^{-2}$ were used as the cathodic catalyst, while Iridium oxide nanoparticles (Johnson Matthey) with a loading of $2 \mathrm{mg} \mathrm{cm}^{-2}$ were used as the anodic catalyst. Composites layers of these catalysts and the Nafion binder (commonly referred to as catalyst layers) were coated by hot-pressing onto the membrane using the decal transfer technique ${ }^{44}$ (as described in the SI in detail). The produced catalyst layers had a thickness of approximately $10 \mu \mathrm{m}$. Carbon paper and a sintered titanium body coated by sputtering with platinum were used as the cathodic and anodic current collectors, respectively. In the cell assembly, the current collectors were pressed onto the membrane electrode assembly (membrane plus electrode coatings). Deionized water was purged along the electrodes through the cell in individual circulation loops for the anode and cathode, respectively. Using the same configurations, a cell with Nafion NR212 membrane (a thickness of approximately $57 \mu \mathrm{m}$ in the wet state) was constructed.

\section{Model Parametrization}

In this section, the measured voltage-current characteristics and gas purities of the in-house made state-of-the-art water electrolyzer cells are used to parameterize the model presented. The procedure to obtain the parameters is illustrated in Figure 2 and elucidated in the following. Table II summarizes all the model parameters determined.

Voltage-current characteristic.-Figure 3 shows the measured voltage-current characteristics of the alkaline and acidic water electrolysis cells. The model parameters for the alkaline cell and the acidic cell with the Nafion N117 are determined according to the scheme illustrated in Figure 2. The parameters of this acidic cell (but with a membrane thickness of $57 \mu \mathrm{m}$ ) are used to predict the voltage-current characteristic of the cell with the Nafion NR212 membrane in order to evaluate the model. As the modeled voltage-current characteristic

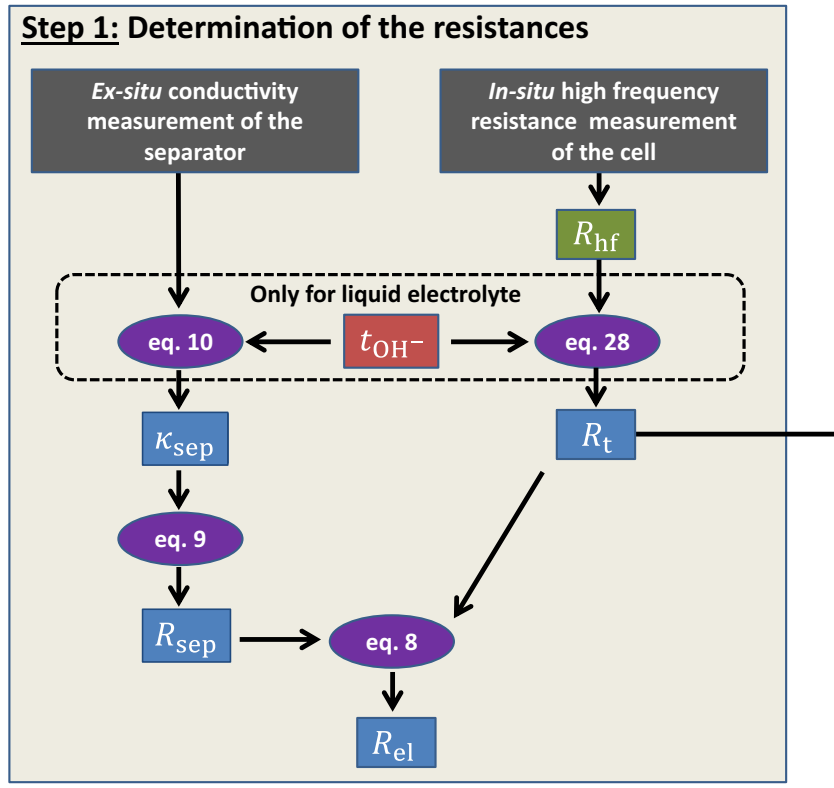

Step 2: Characterization of the gas crossover
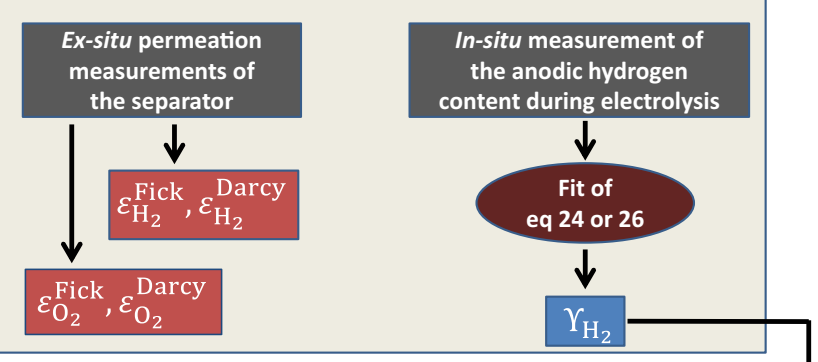

Step 3: Parameterization of the kinetics

Measurement of the

Ul-characteristic of the cell
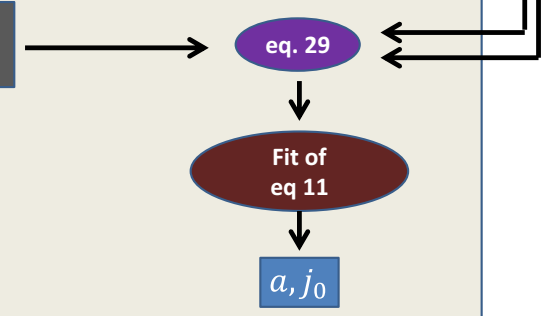

Legend

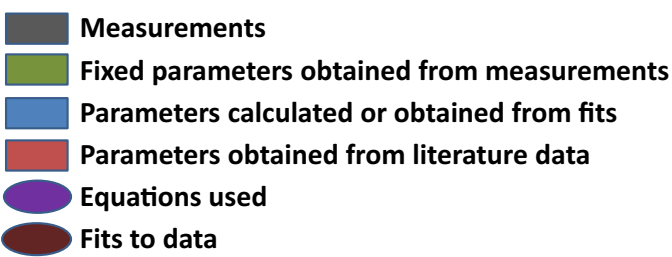

Figure 2. Schematic illustration of the process used to determine the model parameters. The dotted box in which the contributions of the charge transfer coefficient to the conductivity of the liquid alkaline electrolyte is calculated is not required for the parameterization of the acidic PEM water electrolyzer (as discussed in the Resistances section.)

of the cell with the Nafion NR212 membrane and that measured vary by less than $1 \%$, the model is assumed to be valid for all membrane thicknesses. In the case of the alkaline separator, a thinner Zirfon separator is unfortunately commercially not available, so that the cell characteristics cannot be measured for thinner separators. 


\begin{abstract}
Table II. Values of the parameters used for the model with respect to a cell temperature of $80^{\circ} \mathrm{C}$. The kinetic parameters $\left(j_{0}\right.$ and a) and all resistances are normalized to the geometric cell area. Parameters that characterize the separator refer to Nafion N117 immersed in water for the acidic cell and Zirfon soaked with 30 wt $\% \mathrm{KOH}$ for the alkaline cell.
\end{abstract}

\begin{tabular}{cccc} 
Parameter & Acidic & Alkaline & Unit \\
\hline$d$ & $210 \pm 10^{\mathrm{a}}$ & $463 \pm 20^{\mathrm{a}}$ & $\mu \mathrm{m}$ \\
$\kappa_{\text {sep }}$ & $0.167 \pm 0.017^{\mathrm{b}}$ & $0.164 \pm 0.016^{\mathrm{c}}$ & $\mathrm{S} \mathrm{cm}{ }^{-1}$ \\
$R_{\mathrm{hf}}$ & $0.155 \pm 0.011^{\mathrm{d}}$ & $0.246 \pm 0.019^{\mathrm{d}}$ & $\Omega \mathrm{cm}^{2}$ \\
$R_{\mathrm{t}}$ & $0.155 \pm 0.011^{\mathrm{e}}$ & $0.362 \pm 0.040^{\mathrm{e}}$ & $\Omega \mathrm{cm}^{2}$ \\
$R_{\text {sep }}$ & $0.126 \pm 0.013^{\mathrm{f}}$ & $0.281 \pm 0.030^{\mathrm{f}}$ & $\Omega \mathrm{cm}^{2}$ \\
$R_{\mathrm{e}}$ & $0.029 \pm 0.017^{\mathrm{g}}$ & $0.081 \pm 0.065^{\mathrm{g}}$ & $\Omega \mathrm{cm}^{2}$ \\
$a$ & $0.0133^{\mathrm{h}}$ & $0.0308^{\mathrm{h}}$ & $\mathrm{V}$ \\
$j_{0}$ & $2.602 \mathrm{e}-10^{\mathrm{h}}$ & $5.633 \mathrm{e}-6^{\mathrm{h}}$ & $\mathrm{A} \mathrm{cm}$ \\
$\varepsilon_{\mathrm{H}_{2}}^{\text {Fick }}$ & $(5.32 \pm 0.25) \mathrm{e}-11^{\mathrm{i}}$ & $(1.4 \pm 1) \mathrm{e}-12^{\mathrm{i}}$ & $\mathrm{mol} \mathrm{cm}^{-1} \mathrm{~s}^{-1} \mathrm{bar}^{-1}$ \\
$\varepsilon_{\mathrm{O}_{2}}^{\text {Fick }}$ & $(2.52 \pm 0.20) \mathrm{e}-11^{\mathrm{i}}$ & $(0.7 \pm 0.6) \mathrm{e}-12^{\mathrm{i}}$ & $\mathrm{mol} \mathrm{cm}^{-1} \mathrm{~s}^{-1} \mathrm{bar}^{-1}$ \\
$\varepsilon_{\mathrm{H}_{2}}^{\text {Darcy }}$ & $0^{\mathrm{i}}$ & $(1.4 \pm 1) \mathrm{e}-10 \times p_{\mathrm{H}_{2}}{ }^{\mathrm{i}}$ & $\mathrm{mol} \mathrm{cm}^{-1} \mathrm{~s}^{-1} \mathrm{bar}^{-1}$ \\
$\varepsilon_{\mathrm{O}_{2}}^{\text {Darcy }}$ & $0^{\mathrm{i}}$ & $(0.7 \pm 0.5) \mathrm{e}-10 \times p_{\mathrm{O}_{2}}{ }^{\mathrm{i}} \mathrm{mol} \mathrm{cm}^{-1} \mathrm{~s}^{-1} \mathrm{bar}^{-1}$ \\
$\Upsilon_{\mathrm{H}_{2}}, \Upsilon_{\mathrm{O}_{2}}$ & $3 \pm 1^{\mathrm{k}}$ & 0. & $\mathrm{bar} \mathrm{cm}^{2} \mathrm{~A}^{-1}$
\end{tabular}

${ }^{\mathrm{a}}$ Direct thickness measurement.

${ }^{b}$ Literature data ${ }^{29}$ which were obtained by ex-situ electrochemical impedance spectroscopy.

${ }^{\mathrm{c}}$ Estimation of the hydroxide ion conductivity of the Zirfon separator as discussed in the SI.

${ }^{\mathrm{d}}$ Obtained from in-situ impedance spectra at $0 \mathrm{~A} \mathrm{~cm}^{-2}$ (discussed in the SI).

${ }^{\mathrm{e}}$ Acidic: equal to $R_{\mathrm{hf}}$. Alkaline: approximated by Equation 28 .

${ }_{\mathrm{f}}^{\mathrm{A}}$ Approximated by Equation 9.

${ }^{\mathrm{g}}$ Derived from Equation 8.

${ }^{\mathrm{h}}$ Estimated as shown in Figure 4. The errors of the overvoltages that are described by the thus determined parameters are estimated to $10 \%$. ${ }^{i}$ Literature data ${ }^{34,54}$ which were obtained by the electrochemical monitoring technique.

${ }^{\mathrm{j}}$ Estimated by $\varepsilon_{\mathrm{H}_{2}} \approx 0.5 \varepsilon_{\mathrm{O}_{2}}$.

${ }^{\mathrm{k}} \Upsilon_{\mathrm{H}_{2}}$ estimated by the fit to the anodic gas purity graphed in Figure 5 .

The value of $\Upsilon_{\mathrm{O}_{2}}$ is assumed to approximately equal that of $\Upsilon_{\mathrm{H}_{2}}$.

${ }^{1}$ Estimated on the basis of the macroporous electrodes used for the alkaline electrolyzer.

Resistances.-In this section, the first step of the model parameterization that is illustrated in Figure 2 is discussed. In the considered current density range of up to $2 \mathrm{~A} \mathrm{~cm}^{-2}$, the high frequency resistance determined from impedance measurements (as discussed in the SI in detail) was within the measurement precision independent of the current density. The high frequency resistance $R_{\mathrm{hf}}$ of the acidic PEM water electrolyzer obtained from the impedance measurements equals the total ohmic cell resistance $R_{\mathrm{t}}$ (Voltage-current characteristic section). In the case of the alkaline electrolyzer, the charge transfer coefficient (Voltage-current characteristic section) of $30 \mathrm{wt} \% \mathrm{KOH}$ at $80^{\circ} \mathrm{C}$ was estimated to $t_{\mathrm{OH}^{-}} \approx 0.68$ by the procedure presented in the SI. Under the assumption that the cell resistance is dominated by the ion conduction (as later discussed in this section) the total DC resistance $R_{\mathrm{t}}$ of the alkaline cell was determined by dividing the high frequency resistance $R_{\mathrm{hf}}$ by the estimated charge transfer coefficient $t_{\mathrm{OH}^{-}}$(based on Equation 9):

$$
R_{\mathrm{t}} \approx \frac{R_{\mathrm{hf}}}{t_{\mathrm{OH}^{-}}}
$$

The area resistances of the separators $\left(R_{\text {sep }}\right)$ in both systems were approximated on the basis of the conductivities and thicknesses shown in Table II using Equation 9. The proton conductivity of Nafion membranes immersed in water (measured by four wire sensing electrochemical impedance spectroscopy) was reported in the literature. ${ }^{29}$ In the case of the Zirfon separator in combination with liquid $\mathrm{KOH}$ electrolyte, the hydroxide conductivity cannot be measured directly

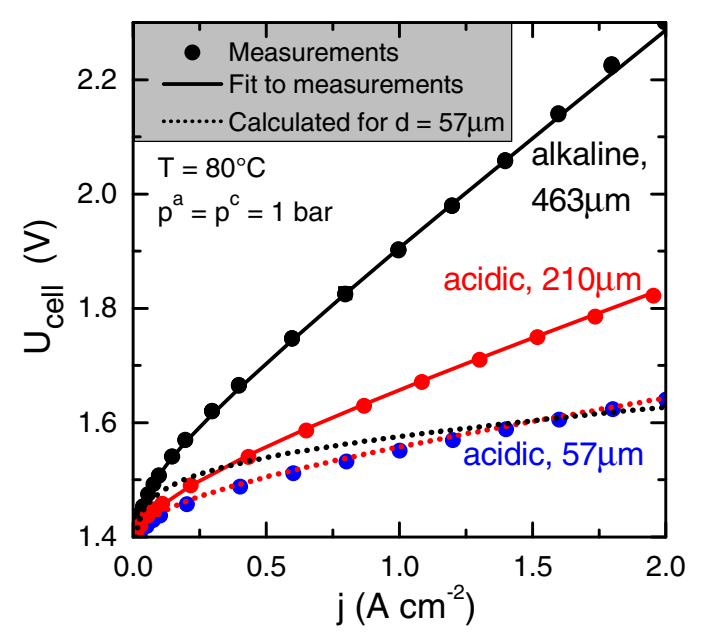

Figure 3. Voltage-current characteristics of the alkaline cell (black) and the acidic cells with a Nafion N117 membrane (wet thickness of $210 \mu \mathrm{m}$, graphed in red) and a Nafion NR212 membrane (wet thickness of $57 \mu \mathrm{m}$, graphed in blue). The measured characteristics are depicted as scatters, while the solid lines represent the fits in the form of Equation 12 to this data with the parameters stated in Table II. The dotted lines show modeled voltage-current characteristic used with the same parameters as the solid black and red lines, respectively, but assuming separator thicknesses of $57 \mu \mathrm{m}, R_{\mathrm{e}}=0$ (Efficiency analysis section) for the alkaline cell and $\Upsilon=2$ bar $\mathrm{cm}^{2} \mathrm{~A}^{-1}$ for the acidic cell (Gas crossover section). During the measurements, cell temperatures of $80^{\circ} \mathrm{C}$ and atmospheric pressures were applied at the anodic and cathodic gas oulets of the cells.

by electrochemical impedance techniques (contributions of the potassium ions to the alternating current also account). On the basis of exsitu electrochemical impedance spectroscopy and the charge transfer coefficient $t_{\mathrm{OH}^{-}} \approx 0.68$, the hydroxide conductivity of Zirfon was estimated to $0.164 \pm 0.020 \mathrm{~S} \mathrm{~cm}^{-1}$ for $30 \mathrm{wt} \% \mathrm{KOH}$ filling at $80^{\circ} \mathrm{C}$ (discussed in the SI). By using Equation 8, the electrode resistances $R_{\text {el }}$ were determined to approximately $82 \pm 68 \mathrm{~m} \Omega$ and $29 \pm 17 \mathrm{~m} \Omega$ for the alkaline and acidic cell (equal to $17 \%$ and $19 \%$ of their overall cell resistances), respectively.

In the case of the alkaline electrolyzer, the influence of the electron conduction in the metallic electrodes on the overall cell resistance can be assumed to be negligible, as the conductivity of metals is typically higher than $1 \times 10^{-4} \mathrm{~S} \mathrm{~cm}^{-1}$ and thus more than four orders of magnitude higher than that of the electrolyte. However, the conductivity of the passivation layer of nickel was reported by Trotochaud et al. ${ }^{45}$ to range between $1 \times 10^{-4} \mathrm{~S} \mathrm{~cm}^{-1}$ and $6.5 \times 10^{-3} \mathrm{~S} \mathrm{~cm}^{-1}$. The passivation layer of metallic nickel was reported to a thickness of less than ten nanometers. ${ }^{46-48}$ The combination of the poor conductivity but small thickness results by using Equation 9 in an area resistance of less than $10 \mathrm{~m} \Omega \mathrm{cm}^{2}$ of each of the passivation layers of the employed nickel components. These area resistances can occur at the interface of the bipolar plates with the electrodes and the electrodes with the electrolyte. When the electrodes are welded onto the bipolar plates, only the resistances of the passivation layers at the anodic and cathodic interfaces between the electrodes and the electrolyte contribute. The dominating contribution to electrode resistance was however ascribed to the holes of $1.6 \mathrm{~mm}$ diameter of the perforated Nickel substrate that was used for the electrodes and their open area of approximately $66 \%$. As a result of these macroporous holes, more than half of the cell area was not permeable to hydroxide ions by the shortest path through the separator between the electrodes. Accordingly, the overall resistance of the ionic conduction between the electrodes increased. The additional resistances arising from this geometric effect are taken into account by the electrode resistance $R_{\mathrm{e}}$.

In the PEM water electrolyzer, contact resistances between the bipolar plates, current collectors and electrodes occurred. At the anode, platinum was sputtered on both sides of the titanium current collector in order to avoid contact resistances by the passivation 

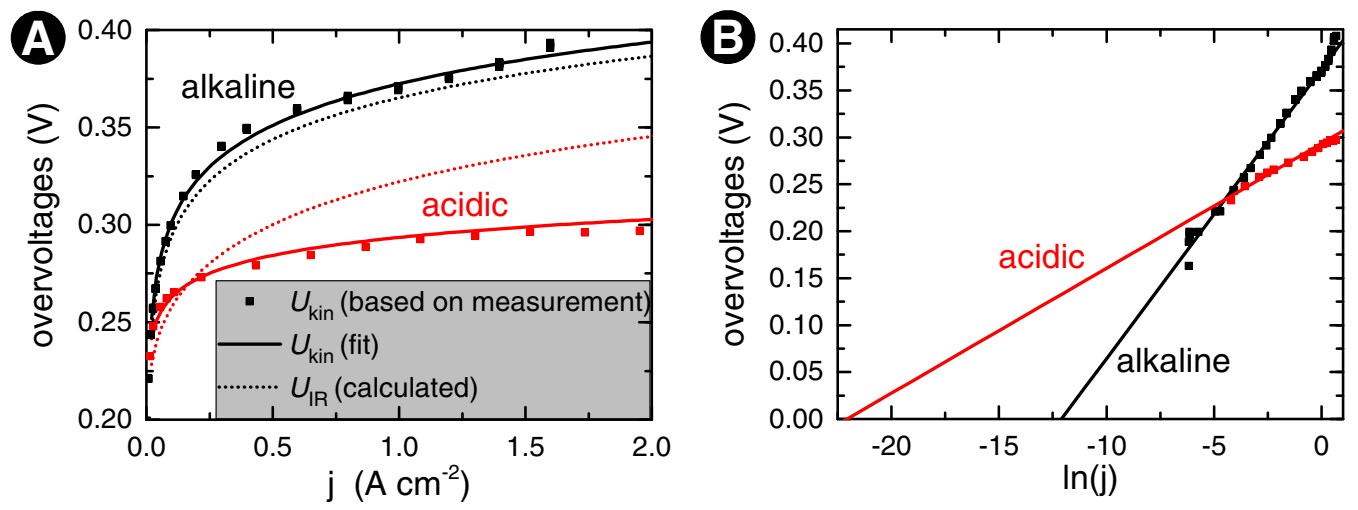

Figure 4. Kinetic overvoltages $U_{\text {kin }}$ and IR-corrected overvoltages $U_{\mathrm{IR}}$ of the alkaline (black) and acidic (red) water electrolyzer as a function of the linear (A) and logarithmic current density (B). Scatter: $U_{\text {kin }}$ obtained from the measurements graphed in Figure 3 via Equation 29 . Solid lines: Fit to $U_{\text {kin }}$ data by Equation 11 for (A) and linear fit for (B). Dotted lines: $U_{\text {IR }}$ calculated by Equation 30. The fit parameters are stated in Table II.

layers on titanium. In the case of fuel cells with similar electrodes as the cathode of the acidic water electrolyzer, the Ohmic resistance of the ion conduction in the catalyst layers was reported to be at least 40 times larger than that of the electron conduction. ${ }^{49}$ At the anode, the conductivity of the anodic iridium oxide ${ }^{50}$ catalyst is approximately $3 \times 10^{4} \mathrm{~S} \mathrm{~cm}^{-1}$, while contact resistances between the catalysts particles may significantly reduce the electric conductivity of the overall catalyst layer. Boyer et al. ${ }^{51}$ approximated the ionic conductivity of catalyst layers as the product of their volume fraction of Nafion binder and the bulk conductivity of the Nafion membrane. Accordingly, the ionic conductivities in the catalyst layers are smaller than that of the membrane and thus have a decisive impact on the overall resistance. To summarize, the main influence on the electrode resistances in the alkaline and acidic water electrolyzer were ascribed to the ion conduction in the electrodes and contact resistances, as the intrinsic electron conductivities of the electrocatalysts were orders of magnitudes higher than that of the electrolytes.

Kinetics.-After determining the resistances, the second step that is illustrated in the scheme in Figure 2 is the parameterization of the partial pressure increase $\left(\Upsilon_{\mathrm{H}_{2}}\right.$ and $\left.\Upsilon_{\mathrm{O}_{2}}\right)$ in the electrodes. These values are parameterized in the Gas crossover section and are now presumed in order to determine the kinetic parameters $j_{0}$ and $a$. Typically, the exchange current densities are normalized to the electrochemically active surface areas of the catalysts. However, bubble coverage and the correlated blocking of the porous electrodes affect the electrochemically active surface areas during water electrolysis. Thus, the electrochemically active surface areas of the examined water electrolyzers during gas evolution are not known. One current exchange density and one Tafel slope were used to describe both, the anodic and cathodic reaction (Eq. 11). This simplification reduced fit parameters but led to the loss of information on the individual overvoltages at the electrodes. Hence, using this description, the kinetic overvoltages at the electrodes cannot be normalized to their electrochemical active surface areas, respectively. As an alternative to the normalization to the electrochemical active surface area, the exchange current densities $j_{0}$ were normalized to the geometric cell area. Consequently, using this description, the overall kinetic overvoltages are influenced by the surfaces and activities of the catalysts.

On the basis of Equation 7, the kinetic overvoltage $U_{\text {kin }}$ can be extracted from the measurements by:

$$
U_{\text {kin }}=U_{\text {cell }}-U_{\mathrm{N}}-R_{\mathrm{t}} j
$$

In Figure 4, the thus obtained kinetic overvoltages are graphed. These data was parameterized with $j_{0}$ and $a$ by fits of Equation 11. To keep the exponential impact of the reactant starvation on the determination of the kinetic parameters $\left(a\right.$ and $j_{0}$ ) as low as possible, the fits to the voltage-current characteristics were applied to low current densities from 0 to $0.4 \mathrm{~A} \mathrm{~cm}^{-2}$. The errors of the kinetic overvolt- ages were estimated to $10 \%$ of the absolute values. Although the fits were conducted at such low current densities, the modeled and measured voltage-current characteristic agreed up to current densities of $2 \mathrm{~A} \mathrm{~cm}^{-2}$. Consequently, the impact of the reactant starvation on the voltage-current characteristic can be estimated to be negligible in the examined cells.

By using the so called 'Tafel plot' $\left(U_{\text {kin }}\right.$ vs. $\left.\ln (j)\right)$ that is graphed in Figure 4B, the kinetic parameters $j_{0}$ and $a$ were also determined. In this depiction the Tafel equation (Eq. 11) linearizes and $j_{0}$ is typically extracted by the intercept of a linear fit to the measurements with the $x$-axis. The slope of the linear fit corresponds to $a$. The measurement of the voltage-current characteristic was conducted at current densities above $10 \mathrm{~mA} \mathrm{~cm}^{-2}$ as toward lower current densities the gas impurities increase (as later discussed in the Gas crossover section). At the cathode, the cross-permeated oxygen can be electrochemically converted and thereby influence the kinetics of the hydrogen evolution. The large gap between the cell current density and $j_{0}$ leads to a large error of its estimation. Moreover, the extrapolation of $j_{0}$ is further influenced by different anodic reaction mechanisms in different current density ranges. ${ }^{52}$ Nevertheless, the overvoltage parameterized by $j_{0}$ and $a$ by the fits of the Tafel equation (Figure 4A) or linear fits in the Tafel plot (Figure 4B) vary by less than $5 \%$, which means that both methods lead within the estimated error to equal results.

Besides the kinetic overvoltages, Figure 4A shows the voltagecurrent characteristic minus the contributions of the ohmic drops and the reversible voltage $\left(1.18 \mathrm{~V}\right.$ at $\left.80^{\circ} \mathrm{C}\right)$, which are in the following defined as the IR-corrected overvoltages $U_{\mathrm{IR}}$. On the basis of Equation 7, these contributions can be calculated by:

$$
U_{\mathrm{IR}}=U_{\mathrm{N}}+U_{\mathrm{kin}}
$$

Offsets between the $U_{\text {kin }}$ and $U_{\text {IR }}$ result from the influence of the water vapor on the Nernst voltage. In the case of the acidic water electrolyzer, more profound differences between both overvoltages arose from the influence of the current density on the partial pressures in the catalyst layers (as described by Equation 4) that consequently increase the Nernst voltage.

The kinetic overpotentials of the alkaline cell were approximately $33 \%$ larger than those of the acidic cell. McCrory et al. ${ }^{20}$ reported similar activities of the employed catalysts in both electrolyzers. Normalized to mass, Raney-Nickel ${ }^{38}$ and the employed Pt catalyst nanoparticles ${ }^{43}$ feature surface areas in the order of $100 \mathrm{~m}^{2} \mathrm{~g}^{-1}$ and $85 \mathrm{~m}^{2} \mathrm{~g}^{-1}$, respectively. In the acidic water electrolyzer, $0.2 \mathrm{mg} \mathrm{cm}^{-2}$ platinum and $2 \mathrm{mg} \mathrm{cm}^{-2}$ iridium oxide were employed, while the catalyst layer had thicknesses of approximately $10 \mu \mathrm{m}$. In contrast, the more than one order of magnitude thicker Raney metal coatings on the electrodes of the alkaline water electrolyzer were far heavier and thus are expected to yield higher overall surface areas. However, bubble blockage in the nanoporous Raney-Nickel alloys might cause 
a significant reduction of the electrochemically active surface areas of the electrodes.

Gas crossover.-In this section, Step 2 of the model parameterization that is illustrated in Figure 2 is discussed. In the Efficiency analysis section, pressures in the order of a few bar during water electrolysis are motivated as reasonable conditions for highly efficient water electrolysis. Based on these deliberations, the hydrogen crossovers in the alkaline and acidic water electrolyzers are here considered for absolute cathodic pressures of 6 bar.

Hydrogen and oxygen diffusivities.-The hydrogen diffusivity in water at $80^{\circ} \mathrm{C}$ can be calculated to approximately $10 \mathrm{~mol} \mathrm{~cm}^{-1} \mathrm{~s}^{-1} \mathrm{bar}^{-1}$ on the basis of literature data. ${ }^{34}$ The hydrogen diffusivity in the aqueous phase in Nafion was reported to be approximately half that of water, ${ }^{53}$ while the permeability of the $30 \mathrm{wt} \%$ $\mathrm{KOH}$ solution is at $80^{\circ} \mathrm{C}$ approximately $9 \%$ of that of water. ${ }^{34}$ The polymeric phase of Nafion was reported to significantly contribute to the overall gas diffusivity, as water penetrating into the solid phase may act as a plasticizer that softens the solid phase and thus increases its gas diffusivity. ${ }^{53}$ In contrast, the solid phase of Zirfon is impermeable to gases. ${ }^{34}$ As a result of these physical material properties, the overall hydrogen diffusivity in Nafion is 38 times higher than that of the Zirfon separator (with reference to the values stated in Table fit-parameters).

Permeabilities of the separators to differential pressures.-In the case of the alkaline electrolyzer, balanced anodic and cathodic pressures are used to keep differential pressure forced electrolyte permeation through the separator and an accompanied convection of dissolved gases as low as possible. In a previous study ${ }^{34}$ we derived a linear relation of the cross-permeation flux through the Zirfon separator forced by the diffusion divided to that forced by convection as described by $\Phi_{\mathrm{H}_{2}}^{\text {Darcy }} \approx \frac{\Delta p}{0.01 \text { bar }} \Phi_{\mathrm{H}_{2}}^{\text {Fick }}$. Assuming that absolute pressure differences smaller than $1 \%$ between the anodic and cathodic compartment are technical realizable, 6 bar operating pressure means $\Delta p=0.06$ bar. With this value, the cross-permeation caused by differential pressures is with reference to the latter equation at maximum sixfold larger than that caused by the diffusion. With respect to the low impact of the diffusion on the overall gas crossover in the alkaline water electrolyzer, the approximation $\Phi_{\mathrm{H}_{2}} \approx \Phi_{\mathrm{H}_{2}}^{\text {Darcy }}$ is used in the following. Accordingly, the anodic hydrogen content and current efficiency of the alkaline water electrolyzer are described by Equations 26 and 27.

In contrast to the porous Zirfon separator, the influence of differential pressures up to 4 bar on the hydrogen cross-permeation flux density through Nafion membranes was reported to be smaller than $1 \% .{ }^{54}$ From a physical point of view, the small pores of Nafion membranes (mean diameter in the order of approximately $2.5 \mathrm{~nm}^{5}$ ) are responsible for this low permeability to differential pressures. In the catalyst layers, mean pore diameters that are one or two orders of magnitude larger than those in Nafion membranes ${ }^{55,56}$ enable the differential pressure driven gas transport. Thus, in the case of the acidic water electrolyzer, the gas cross-permeation through the membrane is dominated by diffusion, which means $\Phi_{\mathrm{H}_{2}} \approx \Phi_{\mathrm{H}_{2}}^{\text {Fick }}$. Accordingly, the anodic hydrogen content and current efficiency of the acidic water electrolyzer are described by Equations 24 and 25. The gastight Nafion membranes allow the operation with different anodic and cathodic pressures. ${ }^{27,31}$

Gas purities.-Figure 5 shows measured and modeled anodic hydrogen contents. In the case of the acidic cells with the Nafion N117 and NR212 membranes, Equation 24 was fitted to the measured anodic hydrogen contents (measurement procedure described in the SI). These fits were conducted with the hydrogen diffusivity in Nafion reported in the literature ${ }^{31}$ (stated in Table II) as fixed parameter, while the cathodic partial pressure increase factor $\Upsilon_{\mathrm{H}_{2}}$ was used as the only free parameter. Within the measurement precision of approximately $0.2 \%$ of the anodic hydrogen content, the modeled data in the form of the fits and the measured data agree. As discussed in the SI in

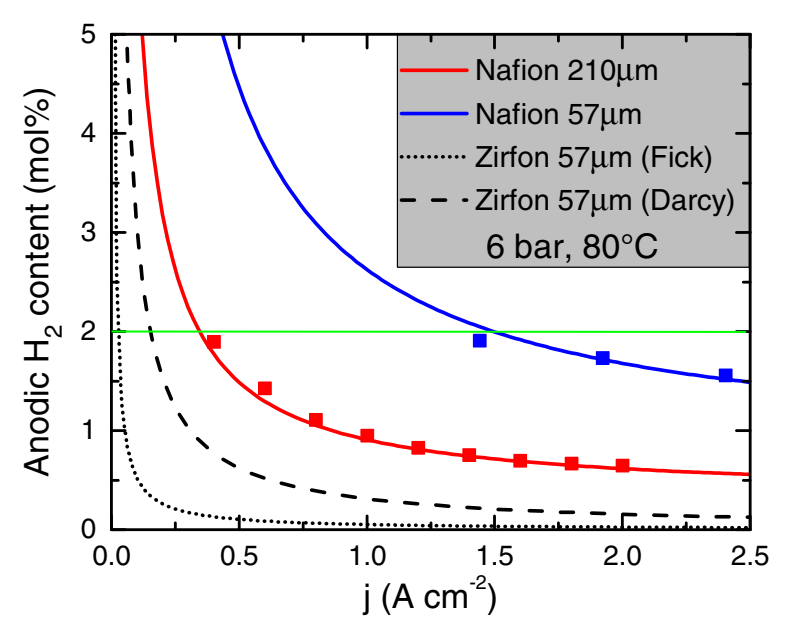

Figure 5. Anodic hydrogen contents of the alkaline cell (black) and acidic cells (red: Nafion N117 membrane, blue: Nafion NR212 membrane) for a temperature of $80^{\circ} \mathrm{C}$ and an absolute cathodic pressure of 6 bar. Green horizontal line: Safety limit (half of the lower explosion limit ${ }^{76}$ of $4 \%$ ). Scatter: Measurements (described in the SI) with atmospheric pressure at the anode. Solid red line: Fit of Equation 24 to the measured anodic hydrogen content. Dotted lines: Modeled anodic hydrogen content by the Fickian diffusion for separator thicknesses of $57 \mu \mathrm{m}$ using Equation 24. Dashed line: Modeled anodic hydrogen content based on the differential pressure driven permeation for $\Delta p=0.06$ bar for the alkaline electrolyzer with a separator thickness of $57 \mu \mathrm{m}$ using Equation 26. All parameters used for the calculations are stated in Table II.

detail, the transport of the evolved gases from the catalyst through the catalyst layers to the gas outlet of the cell is dominated by differential pressures, to which the nanoporous structures of the catalyst layers with mean pore sizes in the order of $60 \mathrm{~nm}^{55}$ show low permeabilities. Consequently, high values of $\Upsilon_{\mathrm{H}_{2}}$ result for the acidic water electrolyzers. In the case of the cell with the Nafion N117 membrane the partial pressure increase factor was determined by the fit to $\Upsilon=3$ bar cm $\mathrm{A}^{-1}$, while that of the cell with the Nafion NR212 membrane was determined to $\Upsilon_{\mathrm{H}_{2}}=2 \mathrm{bar} \mathrm{cm}^{2} \mathrm{~A}^{-1}$. The differences resulted from variations of the porosity of the catalyst layers, which are not fully reproducible. Thus, the parameter $\Upsilon_{\mathrm{H}_{2}}$ was characterized by a large error (see Table II).

Oxygen that permeates from the anode to the cathode is catalytically recombined to water, so that oxygen impurities in the anodic hydrogen content are typically negligible. The partial pressure increase factor $\Upsilon_{\mathrm{O}_{2}}$ thus cannot be measured by the cathodic hydrogen content. Under the assumption that the morphologies of the anodic and cathodic catalyst layers are similar, $\Upsilon_{\mathrm{O}_{2}}$ is parameterized with the same value as $\Upsilon_{\mathrm{H}_{2}}$.

In the model for the gas crossover, the influence of convection by ion-transport on the gas crossover is not considered. In the case of the acidic water electrolyzer, the proton flux forced by the electrochemical reactions permeates from the anode to the cathode. When this proton flux carries dissolved hydrogen molecules, these permeate in the opposing direction to those that diffuse along the concentration gradient from the cathode to the anode. Accordingly, the proton movement through the membrane is expect to decrease the anodic hydrogen content. However, such an effect on the measured gas purities of the acidic water electrolysis cells could not be observed, as with the parameterization of the fits by $\varepsilon_{\mathrm{H}_{2}}^{\text {Fick }}$ and $\Upsilon_{\mathrm{H}_{2}}$ a good agreement to the measurements was obtained. In the SI, the interaction between the ion migration and the gas diffusion in the separators is physically described and discussed.

In the case of the alkaline water electrolysis cell, we could not realize in-operando measurements of the anodic hydrogen content under pressure because of safety constraints related to the pressurized operation with liquid bases. As an alternative, the ex-situ characterization 
of the hydrogen and oxygen permeabilities of the Zirfon separator discussed and an absolute pressure difference of $1 \%$ between the anodic and cathodic compartment were used to model the gas crosspermeation. A negligible partial pressure increase factor $\Upsilon_{\mathrm{H}_{2}}$ was assumed for the alkaline water electrolyzer, as the perforated metal electrodes with holes of $1.6 \mathrm{~mm}$ diameter are highly permeable to the differential pressure driven gas permeation from the catalyst to the gas outlet of the cell. Figure 5 shows the modeled anodic hydrogen content of the alkaline water electrolyzer for a cathodic pressure of 6 bar and an assumed separator thickness of $57 \mu \mathrm{m}$. As graphed in this figure, the anodic hydrogen content of the acidic water electrolyzer was calculated to be approximately ten times higher than that of the alkaline water electrolyzer. High gas purities during alkaline water electrolysis at atmospheric pressure operation with Zirfon separators and similar electrodes were also reported in an experimental study of Vermeiren et al., ${ }^{35}$ which are in agreement with those predicted by the model.

List of model uncertainties.-Uncertainties that affect the model predictions arise from the errors of the parameters and the assumptions or simplifications used. All parameters that were experimentally determined or that were extracted from the literature were characterized by an error. However, some parameters were estimated, as their measurement could not be realized. In summary, these parameters are: (i) $\Upsilon_{\mathrm{O}_{2}}$ for the acidic water electrolyzer, which was assumed to equal the value of $\Upsilon_{\mathrm{H}_{2}}$ (Gas purities section). (ii) $\Upsilon_{\mathrm{H}_{2}}$ and $\Upsilon_{\mathrm{O}_{2}}$ for the alkaline water electrolyzer. With reference to the macroporosity of the electrodes, their values were estimated to zero (Gas purities section). (iii) $\Delta p$ during balanced pressure operation, which is relevant for the differential pressure driven cross-permeation through the Zirfon separator (described by Equation 23). The precision of the applied pressures is a technical question and was estimated to $1 \%$ of the absolute pressures applied with reference to commercially available pressure controllers. (iv) $U_{\mathrm{rs}}$, which was assumed to be negligible on the basis of the form of the measured voltage-current characteristics (Kinetics section). (v) $\varepsilon_{\mathrm{O}_{2}}^{\text {Fick }}$ for the alkaline water electrolyzer was assumed to be half as large as $\varepsilon_{\mathrm{H}_{2}}^{\text {Fick }}$ (this is a typical relation of the diffusivities of both gases in aqueous solutions). This value is not used for the calculations as differential pressure driven permeation dominates the gas crossover.

Assumptions and simplifications that were used in the model are: (i) A negligible influence of the ion migration on the gas diffusion, which was justified on the basis of the form of the measured anodic hydrogen content of the acidic water electrolyzer as a function of the current density (Gas purities section). (ii) The pressure drop in the electrodes was derived on the basis of simple physical laws to be proportional to the current density (Pressure increase by gas evolution section), while the fluid dynamics on the microscale of the electrode are not known. The derived linear relation between the partial pressures of the gases in the electrodes to the current density in the form of Equation 4 led to a good agreement of the fitted and measured anodic gas purity of the acidic water electrolyzer (Figure 5). Thus, the derived relation in the form of Equation 4 is considered to give a good approximation of the gas transport in the electrodes. (iii) The assumption for the heat balance in the form of a negligible heat dissipation into the environment and the Equations 15 and 16 display a simplified and generalized approach to describe the complex heat transfer processes in electrolyzers. In detail, these processes depend on the design of the electrolyzer and thus cannot be described in detail by the universal model presented. Despite the model precision could be enhanced when the above mentioned parameters and processes could be described more precisely, the modeled cell voltage and the anodic hydrogen content in the considered current density range deviate by less than $10 \%$ from the absolute values.

\section{Efficiency Analysis}

In this section, first the efficiencies of the characterized alkaline and acidic water electrolyzer are modeled on the basis of the parameters determined in the previous section. Second, prospects to improve the cell efficiencies are discussed.

Comparison of the efficiencies. - In order to model and compare the cell efficiencies of the presented electrolyzers, following assumptions are used: (i) Stationary cell currents. (ii) Negligible heat dissipation into environment as realizable by good thermal insulation and large electrolyzers with small ratios of area to volume. (iii) Constant cell temperatures of $80^{\circ} \mathrm{C}$. The influence of the heat balance on the cell efficiency are modeled using the assumptions discussed in Heat balance section. (iv) The same separator thicknesses of $50 \mu \mathrm{m}$ for both cells. In the case of the Nafion, such thin membranes are commercially available and show in terms of conductivity and gas diffusivities equal properties in comparison to thicker membranes. ${ }^{29,34}$ In the case of the Zirfon separator, this assumption implements that the same material but with a reduced thickness could be produced. The physical properties of this separator in terms of the conductivity and permeability are probably not influenced by the thickness reduction, as these material constants (which are independent of the material geometry) are determined by the electrolyte filling and the pore geometry. (iv) Porous electrodes for the alkaline electrolyzer, where the overall area of the Zirfon separator can be used for the direct hydroxide conduction between the electrodes. Moreover, these electrodes are assumed to be welded onto the bipolar plate in order to avoid contact resistances. Accordingly, $R_{\mathrm{e}} \approx 0 \Omega$ could be realized for the alkaline electrolyzer. (v) 6 bar cathodic pressures (as motivated in the next paragraph). (vi) Absolute pressures differences of $1 \%$ between the anodic and cathodic compartment during balanced pressure operation of the alkaline electrolyzer.

In the case of the alkaline water electrolyzer, balanced pressure must be applied in order to avoid high cross-permeation fluxes of the electrolyte and gases through the porous separator. In contrast, PEM water electrolysis can be conducted at differential pressures, which reduces the oxygen cross-permeation flux and the Nernst voltage. The saturated vapor pressure of water at $80^{\circ} \mathrm{C}$ equals $0.49 \mathrm{bar}^{25}$ while that of the $30 \mathrm{wt} \% \mathrm{KOH}$ solution equals approximately 0.31 bar. ${ }^{26} \mathrm{Using}$ these values, the thermobalanced voltages of the water electrolyzers were calculated on the basis of Equations 13 and 14. At atmospheric pressure operation of the PEM water electrolyzer, the thermobalanced voltage is $1.742 \mathrm{~V}$, which is the result of $49 \mathrm{~mol} \%$ water content in the product gases. At a cathodic pressure of 6 bar and atmospheric anodic pressure the thermobalanced voltage equals $1.617 \mathrm{~V}$, while a pressurization of the anode to 2 bar reduces the thermobalanced voltage to $1.580 \mathrm{~V}$. Higher anodic pressures further reduce the thermobalanced voltage at maximum by approximately $50 \mathrm{mV}$ but significantly increase the oxygen crossover. Hence, 2 bar anodic pressure is taken as compromise to reduce the thermobalanced voltage at a moderate oxygen cross-permeation rate. In the case of the alkaline water electrolyzer at 6 bar operating pressure, the lower vapor pressure of $\mathrm{KOH}$ and the mandatory balanced pressure operation lead to a thermobalanced voltage of $1.5443 \mathrm{~V}$. This voltage is approximately $5037 \mathrm{mV}$ smaller than that of the PEM water electrolyzer for the discussed conditions.

Figure 6A shows the modeled current, voltage and cell efficiencies of both water electrolyzers. In Figure 6B, the cell efficiencies of the alkaline and acidic water electrolyzer are plotted by taking into account the errors of the parameters that are stated in Table II. The modeled cell efficiency for the alkaline water electrolyzer is below current densities of $0.5 \mathrm{~A} \mathrm{~cm}^{-2}$ significantly higher than that of the acidic water electrolyzer, which can be attributed to the smaller thermobalanced voltage and gas cross-permeation. At higher current densities, the modeled efficiencies of the alkaline and acidic water electrolyzer are approximately equal, which can be attributed to a reduced impact of the current efficiency and higher cell voltages than the thermoneutral voltages. With the used assumption of $1 \%$ deviation between the absolute pressures in the anodic and cathodic compartment, the current efficiency of the alkaline water electrolyzer is approximately ten times higher than that of the acidic water electrolyzer. Toward higher 

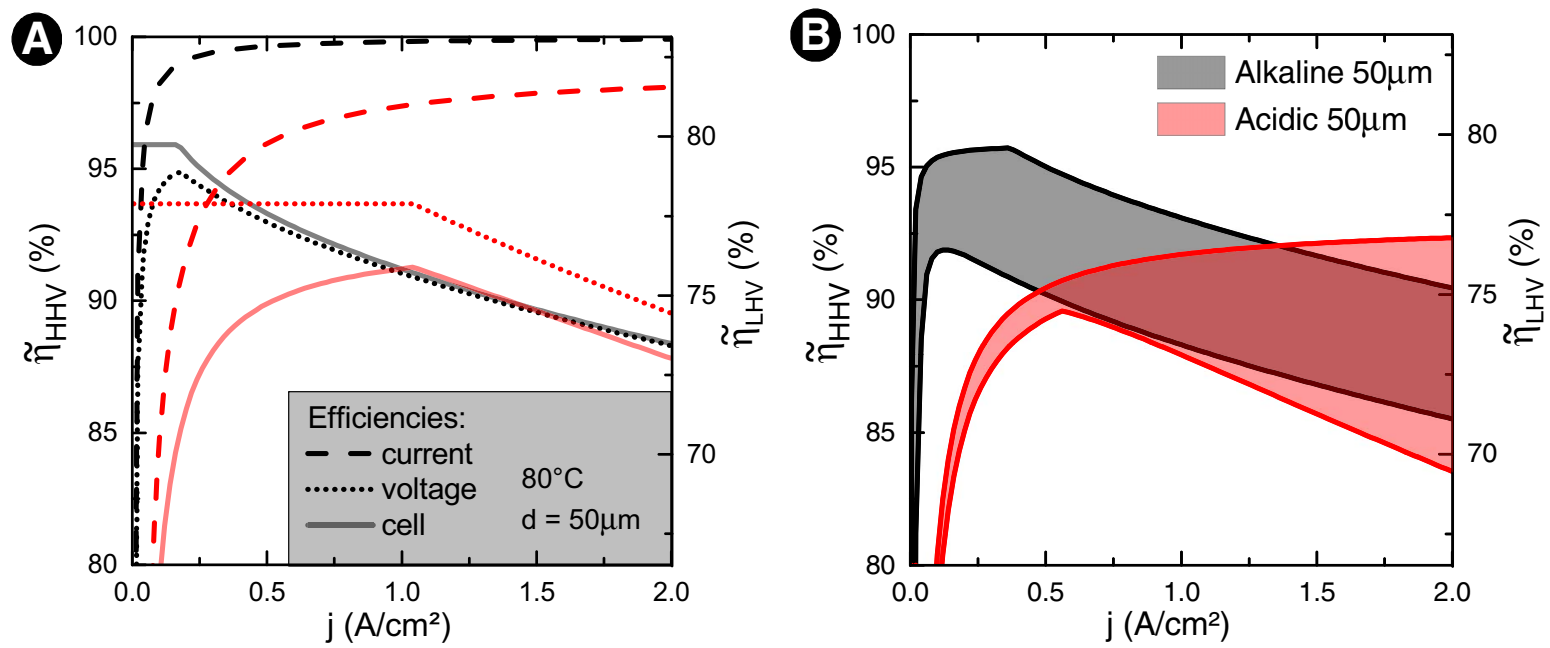

Figure 6. (A): Modeled cell efficiencies of the alkaline (black) and acidic PEM (red) water electrolyzer for separator thicknesses of $50 \mu \mathrm{m}$ and a temperature of $80^{\circ} \mathrm{C}$ using the equations summarized in the Calculation of the cell efficiency section and the parameters stated in Table II. As motivated in the text, $p^{\mathrm{a}}=p^{\mathrm{c}}=6 \mathrm{bar}$ were assumed for the alkaline cell while $p^{\mathrm{a}}=6 \mathrm{bar}$ and $p^{\mathrm{a}}=2 \mathrm{bar}$ were used to model the acidic cell. Dotted lines: Voltage efficiencies including heat balance. Dashed lines: Current efficiencies. Solid lines: Cell efficiencies. Left scale: Scale for the current efficiency, while voltage and cell efficiencies are normalized to the higher heating value. Right scale: Voltage and cell efficiency normalized to the lower heating value. (B): Error analysis of the cell efficiencies plotted in (A). The smallest and highest efficiencies that result from the experimentally determined parameters at the margins of their error range was plotted. The area between highest and lowest efficiencies was shaded gray for the alkaline cell and red for the acidic cell.

pressures the gas crossover will more negatively affect the total efficiency of the acidic cell than that of the alkaline cell.

Perspectives for efficiency improvement.-With reference to the efficiency analysis presented, perspectives to increase the efficiency of water electrolyzers are listed in the following.

Ionic conductivity.-In Table II, similar direct current conductivities of the Nafion membrane and the Zirfon separator filled $30 \mathrm{wt} \%$ $\mathrm{KOH}$ are displayed. By variations of the weight composition of the $\mathrm{KOH}$ solution a significant increase of the conductivity cannot be achieved, as the used $30 \mathrm{wt} \% \mathrm{KOH}$ solution is close to the maximum conductivity of the aqueous $\mathrm{KOH}$ solutions at $80^{\circ} \mathrm{C} .{ }^{41}$ The proton concentration in the aqueous phase of Nafion immersed in water was reported as $2.5 \pm 0.5 \mathrm{M}$ with a similar proton mobility as that in aqueous $\mathrm{HCl}$ solutions. ${ }^{29}$ The maximium conductivity of aqueous $\mathrm{HCl}$ solutions at $65^{\circ} \mathrm{C}$ is at a concentration of approximately $5.5 \mathrm{M}^{57}$ (data for higher temperatures could not be found), which is approximately 1.3 times higher than that at $2.5 \mathrm{M}$. Hence, an increase of the conductivity in Nafion-type polymer electrolyte membranes may be achievable by increasing the proton concentration in the aqueous phase. However, such higher proton concentrations could lead to excessive water uptake and the loss of the structural integrity. In the literature, ${ }^{29,34}$ the influence of the water channel morphology of Nafion and Zirfon were estimated to reduce their overall conductivities by a factor of approximately 0.15 and 0.16 in comparison to the conductivities of their aqueous phases, respectively. When smaller tortuosities of the pores in both materials can be realized, higher overall conductivity can be expected.

Gas crossover-The high hydrogen and oxygen diffusivities of the aqueous and solid phase in Nafion membranes ${ }^{53}$ have a chief impact on the cell efficiency especially at high pressures and low current densities. ${ }^{31}$ In contrast, the gas diffusivities in the solid phase of the Zirfon separator were estimated to be negligible. In addition, the hydrogen and oxygen diffusivity and solubility in aqueous alkaline solutions are lower than those in acidic solutions. ${ }^{58-60}$ As a result and with reference to the values stated in Table II, the diffusivity of hydrogen in Zirfon with $30 \mathrm{wt} \% \mathrm{KOH}$ filling is approximately 38 times smaller than that in Nafion membranes. Polymer electrolyte membranes with lower gas diffusivities in the solid phase may be realized by cross-linking of the polymer matrix. ${ }^{53}$ Higher proton concentrations in aqueous solution slightly decrease the gas diffusivities, ${ }^{58,61}$ which might by also valid for the aqueous phase in PEMs. In contrast, the diffusivity in alkaline solutions decreases strongly toward higher hydroxide ion concentrations. ${ }^{34,58,62}$ A reduction of the pore diameters of alkaline separators could decrease differential pressure driven electrolyte cross-permeation which dominates the gas crossover in the alkaline cell. ${ }^{34}$

Operation parameters.-A disadvantage of liquid alkaline electrolytes in combination with porous separators is the limitation to balanced pressures. ${ }^{34}$ Thus, a reduction of the Nernst voltage by using differential pressure operation (as possible for PEM water electrolyzers) cannot be realized by employing porous separators with liquid alkaline electrolytes. The use of forthcoming stable anion exchange membranes ${ }^{63}$ may enable differential pressure operation of water electrolysis with alkaline electrolytes. However, $\mathrm{KOH}$ solutions for alkaline water electrolyzers show lower saturated vapor pressures than water. Accordingly, smaller thermobalanced voltages for the gas evolution in alkaline solutions than that in pure water (which is supplied to PEM water electrolyzers) result.

Higher temperature decrease the Ohmic drop and kinetic overvoltages but increase the thermobalanced voltage. In order to mitigate this increase of the thermobalanced voltage toward high temperatures, higher pressures can be applied (see discussion in the Comparison of the efficiencies section). However, higher pressure increase the gas crossover and consequently decrease the current efficiency. Hence, in order to realize efficient high temperature and high pressure operation of water electrolysis, low hydrogen and oxygen diffusivities of the electrolyte are required, as fulfilled by alkaline $\mathrm{KOH}$ solutions. Thus, high temperature and pressure operation at simultaneously high current efficiencies might be an opportunity to reduce Ohmic and kinetic losses of alkaline water electrolysis. ${ }^{11}$ In the case of acidic water electrolyzers with Nafion-type membranes, the structural integrity (increase of creeping when temperature comes closer to the glass transition temperature) and the high gas diffusivities might limit an increase of the temperature and pressure range during operation.

Electrocatalysts and electrodes:--One of the greatest advantages of alkaline water electrolyzers is the fact that a variety of abundant, cheap and non-noble metals are suitable as catalyst materials. ${ }^{64-66}$ The 
combination of these non-noble metals in the form of alloys can be used to tune the activity of electrocatalysts. ${ }^{20,64,67}$ Abundant metals can be used in large amounts at moderate costs in order to realize high surface area electrodes with thick active layers such as Raney-nickel alloys. ${ }^{37,68,69}$ A chief improvement for the electrodes of the alkaline electrolysis cell might be realizable by microporous frameworks (such as foams ${ }^{70,71}$ or finely woven meshes ${ }^{72}$ ) so that the overall geometric cell area can be utilized.

In the acidic regime, the scarce and costly platinum group transition metals are the only moderately stable and simultaneously active catalysts for hydrogen and oxygen evolution. ${ }^{20}$ At the anode, their slow dissolution ${ }^{73,74}$ might be an issue for long time operation with low loadings. The amount of the precious metal catalysts that can be technically used in electrodes of acidic water electrolyzers is limited by their costs. An increase of the surface area with respect to the same mass of precious metal catalysts is realizable by nanostructured catalysts, while the stability of such nanostructures are challenging in the oxidizing anodic regime. ${ }^{75} \mathrm{~A}$ tremendous improvement of the voltage-current characteristic and the gas purities of PEM based water electrolyzers may be realizable by catalyst layers with higher porosities that could decrease the partial pressure increase factor $\Upsilon_{\mathrm{H}_{2}}$.

\section{Summary}

In this study, the voltage-current characteristic, hydrogen and oxygen cross-permeation, heat balance and cell efficiency of lowtemperature water electrolysis were described by a simple but precise physical model. This model was parameterized with experimental data of state-of-the-art acidic and alkaline water electrolyzers, in order to compare performance differences that are caused by the different nature of the electrolytes, electrodes and electrocatalysts. The main difference of the voltage-current characteristics was a higher cell resistance of the alkaline water electrolyzer, which mainly can be attributed to the employed macroporous electrodes and the thicker separator (appr. $460 \mu \mathrm{m}$ ) in comparison to the membranes of the acidic water electrolyzers (appr. $57 \mu \mathrm{m}$ and $210 \mu \mathrm{m}$ ). Conductivities of the alkaline and acidic electrolyte were found to be equal within the measurement precision, which means that the same distances between the electrodes in both cells result in approximately equal Ohmic drops. Overvoltages related to the kinetics were found to be approximately $30 \%$ smaller for the acidic water electrolyzer. The 38-fold lower hydrogen diffusivity in the alkaline separator than that of the Nafion membrane used for the acidic water electrolyzer was found to display a great advantage of alkaline water electrolysis. The prospects of both technologies were discussed based on the scientific comparison presented. In summary, state-of-the-art alkaline cells but with thinner separators and microporous electrodes were modeled to enable better efficiency than those of cells with acidic Nafion membranes.

\section{Acknowledgment}

This research was supported by the German Federal Ministry of Economic Affairs and Energy under grant No. 03ESP106A. We thank Günter Schiller of the German Aerospace Center for the Raney-Nickel alloy coatings of the electrodes that were used for the alkaline water electrolyzer.

\section{List of Symbols}

a Tafel slope, $\mathrm{V}$

$a_{\mathrm{h}_{2} \mathrm{O}} \quad$ Activity of water, dimensionless

$d \quad$ Separator thickness, $\mu \mathrm{m}$

$D_{\mathrm{H}_{2}} \quad$ Diffusion coefficient for hydrogen, $\mathrm{cm}^{2} \mathrm{~s}^{-1}$

$E_{\text {supply }} \quad$ Energy required to heat the supplied water, $\mathbf{J}$

$H_{\mathrm{ev}}^{\mathrm{gas}} \quad$ Heat of vaporization spend for water vapor in the produced gases, J

I Current, A

$I_{\text {loss }} \quad$ Current loss, A j Current density, $\mathrm{A} \mathrm{cm}^{-2}$

$j_{\text {loss }} \quad$ Current loss normalized to cell area, $\mathrm{A} \mathrm{cm}^{-2}$

$j_{0} \quad$ Exchange current density, $\mathrm{A} \mathrm{cm}^{-2}$

$K \quad$ Permeability of a separator to a electrolyte, $\mathrm{m}^{2}$

$p^{\mathrm{a}} \quad$ Pressure at the anodic gas outlet, bar

$p^{\mathrm{c}} \quad$ Pressure at the cathodic gas outlet, bar

$p_{\mathrm{H}_{2}}^{\mathrm{c}} \quad$ Partial hydrogen pressure in the cathode, bar

$p_{\mathrm{O}_{2}}^{\mathrm{a}} \quad$ Partial oxygen pressure in the anode, bar

$p_{\mathrm{sv}} \quad$ Saturated vapor pressure, bar

$\Delta p \quad$ Pressure difference between the anodic and cathodic compartment, bar

$\Delta p_{\mathrm{H}_{2}} \quad$ Partial pressure difference of hydrogen between the cathode and anode, bar

$P_{\text {heat }} \quad$ Heat power, W

$P_{\text {ideal }} \quad$ Ideal (thermodynamic) power for the production of a certain hydrogen flux, W

$P_{\text {real }} \quad$ Spend power for the production of a certain hydrogen flux,

$R_{\mathrm{e}} \quad$ Electrode resistance, $\Omega \mathrm{cm}^{2}$

$R_{\mathrm{hf}} \quad$ High frequency cell resistance, $\Omega \mathrm{cm}^{2}$

$R_{\text {sep }} \quad$ Separator resistance, $\Omega \mathrm{cm}^{2}$

$R_{\mathrm{t}} \quad$ Total resistance, $\Omega \mathrm{cm}^{2}$

$S_{\mathrm{H}_{2}} \quad$ Hydrogen solubility, mol cm ${ }^{-3} \mathrm{bar}^{-1}$

$t_{\mathrm{OH}^{-}} \quad$ Charge transfer coefficient of hydroxide ions in $\mathrm{KOH}$, dimensionless

$T \quad$ Temperature, $\mathrm{K}$

$U_{\Omega} \quad$ Ohmic drop, $\mathrm{V}$

$U_{\text {cell }} \quad$ Cell voltage, $\mathrm{V}$

$U_{\text {IR }} \quad$ IR-corrected overvoltage, $\mathrm{V}$

$U_{\text {kin }} \quad$ Kinetic overvoltage, $\mathrm{V}$

$U_{\mathrm{N}} \quad$ Nernst voltage, $\mathrm{V}$

$U_{\text {ref }} \quad$ Thermodynamic reference voltage, $\mathrm{V}$

$U_{\text {rev }} \quad$ Reversible voltage, $\mathrm{V}$

$U_{\mathrm{rs}} \quad$ Overvoltage caused by reactant starvation, $\mathrm{V}$

$U_{\mathrm{tb}} \quad$ Thermobalanced voltage, $\mathrm{V}$

\section{Greek}

$\eta \quad$ Efficiency (general), dimensionless

$\eta_{\text {cell }} \quad$ Cell efficiency, dimensionless

$\eta_{\mathrm{C}} \quad$ Current efficiency, dimensionless

$\eta_{\mathrm{U}} \quad$ Voltage efficiency, dimensionless

$\tilde{\eta}_{\text {cell }} \quad$ Cell efficiency (including heat balance), dimensionless

$\tilde{\eta}_{\mathrm{HHV}} \quad$ Cell efficiency normalized to the higher heating value (including heat balance), dimensionless

$\tilde{\eta}_{\text {LHV }} \quad$ Cell efficiency normalized to the lower heating value (including heat balance), dimensionless

$\tilde{\eta}_{U} \quad$ Voltage efficiency (including heat balance), dimensionless

$\varepsilon_{\mathrm{H}_{2}}^{\text {Fick }} \quad$ Hydrogen diffusivity, mol cm $\mathrm{cm}^{-1} \mathrm{~s}^{-1} \mathrm{bar}^{-1}$

$\varepsilon_{\mathrm{H}_{2}}^{\mathrm{H} \text { Darcy }}$ Hydrogen permeability caused by differential pressures,

$\Gamma_{\mathrm{H}_{2}}$ mol cm ${ }^{-1} \mathrm{~s}^{-1}$ bar $^{-1}$

$\mathrm{H}_{\mathrm{H}_{2}} \quad$ Hydrogen production rate, $\mathrm{mol} \mathrm{s}^{-1} \mathrm{~cm}^{-2}$

$\kappa_{\text {sep }} \quad$ Conductivity of the separator, $\mathrm{S} \mathrm{cm}^{-1}$

$\kappa_{\mathrm{OH}^{-}} \quad$ Hydroxide conductivity of $\mathrm{KOH}$ solutions, $\mathrm{S} \mathrm{cm}^{-1}$

$\kappa_{\mathrm{KOH}}$ Total conductivity of $\mathrm{KOH}, \mathrm{S} \mathrm{cm}^{-1}$

$\mu \quad$ Electrolyte viscosity, bar s

$\Phi_{\mathrm{H}_{2}} \quad$ Hydrogen cross-permeation flux density, $\mathrm{mol} \mathrm{s}^{-1} \mathrm{~cm}^{-2}$

$\Phi_{\mathrm{O}_{2}} \quad$ Oxygen cross-permeation flux density, $\mathrm{mol} \mathrm{s}^{-1} \mathrm{~cm}^{-2}$

$\Phi_{\mathrm{H}_{2}}^{\text {Darcy }}$ Hydrogen cross-permeation flux density caused by the diffusion, $\mathrm{mol} \mathrm{s}^{-1} \mathrm{~cm}^{-2}$

$\Phi_{\mathrm{H}_{2}}^{\text {Fick }} \quad$ Hydrogen cross-permeation flux density driven by differential pressures, $\mathrm{mol} \mathrm{s}^{-1} \mathrm{~cm}^{-2}$

$\Upsilon_{\mathrm{H}_{2}} \quad$ Hydrogen partial pressure increase factor at the cathode, bar $\mathrm{cm}^{2} \mathrm{~A}^{-1}$ 
$\Upsilon_{\mathrm{O}_{2}} \quad$ Oxygen partial pressure increase factor at the anode, bar $\mathrm{cm}^{2} \mathrm{~A}^{-1}$

\section{References}

1. W. Kreuter and H. Hofmann, International Journal of Hydrogen Energy, 23(8), 661 (1998).

2. D. L. Stojic, M. P. Marceta, S. P. Sovilj, and S. S. Miljanic, Journal of Power Sources, 118(1-2), 315 (2003).

3. M. Carmo, D. L. Fritz, J. Mergel, and D. Stolten, International Journal of Hydrogen Energy, 8(1), 4901 (2013).

4. K.-D. Kreuer, Chemistry of Materials, 26(1), 361 (2014)

5. F. I. Allen, L. R. Comolli, A. Kusoglu, M. A. Modestino, A. M. Minor, and A. Z. Weber, ACS Macro Letters, 4(1), 1 (2015).

6. E. J. Roche, M. Pineri, R. Duplessix, and A. M. Levelut, Journal of Polymer Science: Polymer Physics Edition, 19(1), 1 (1981).

7. M. R. Hibbs, M. A. Hickner, T. M. Alam, S. K. Mcintyre, C. H. Fujimoto, C. J. Cornelius, and V. Pennsyl, Chem. Matter, 20(3), 2566 (2008).

8. C. C. Pavel, F. Cecconi, C. Emiliani, S. Santiccioli, A. Scaffidi, S. Catanorchi, and M. Comotti, Angewandte Chemie, 126(5), 1402 (2014).

9. M. Felgenhauer and T. Hamacher, International Journal of Hydrogen Energy, 40(5), 2084 (2015).

10. K. Zeng and D. Zhang, Progress in Energy and Combustion Science, 36(3), 307 (2010).

11. J. Divisek, P. Malinowski, J. Mergel, and H. Schmitz, International Journal of Hydrogen Energy, 10(6), 383 (1985).

12. M. M. Jaksic, Journal of New Materials for Electrochemical Systems, 3.2, 153 (2000).

13. J. Greeley, T. F. Jaramillo, J. Bonde, I. B Chorkendorff, and J. K. Nørskov, Nature Materials, 5(11), 909 (2006)

14. E. Fabbri, A. Habereder, K. Waltar, R. Kötz, and T. J. Schmidt, Catal. Sci. Technol., 4(11), 3800 (2014).

15. B. Conway and J. O. M. Bockris, Nature, 178, 488 (1956).

16. B. Hammer, Advances in Catalysis, 45, 71 (2000).

17. A. Garat and J. M. Gras, International Journal of Hydrogen Energy, 8(9), 681 (1983).

18. R. Subbaraman, D. Tripkovic, K.-C. Chang, D. Strmenik, A. P. Paulikas, P. Hirunsit, M. Chan, J. Greeley, V. Stamenkovic, and N. M. Markovic, Nature Materials, 11(6), $550(2012)$.

19. C. C. L. McCrory, S. Jung, J. C Peters, and T. F. Jaramillo, Journal of the American Chemical Society, 135, 16977 (2013).

20. C. C. L. McCrory, S. Jung, I. M. Ferrer, S. M. Chatman, J. C. Peters, and T. F. Jaramillo, J. Am. Chem. Soc., 137(13), 4347 (2015).

21. M. Pourbaix, Atlas of Electrochemical Equilibria in Aqueous Solutions, 2 edition, NACE International, Cecelcor, Houston, Brussely (1974).

22. R. L. LeRoy, C. T. Bowen, and D. J. Leroy, Journal of the Electrochemical Society, 127(9), 1954 (1980).

23. Y. Tanaka, K. Kikuchi, Y. Saihara, and Z. Ogumi, Electrochimica Acta, 50(25-26), 5229 (2005).

24. K. Kikuchi, S. Nagata, Y. Tanaka, Y. Saihara, and Z. Ogumi, Journal of Electroanalytical Chemistry, 600(2), 303 (2007).

25. National Institute of Standards and Technology, http://webbook.nist.gov/ chemistry/fluid/

26. J. Balej, International Journal of Hydrogen Energy, 10(4), 233 (1985).

27. F. Marangio, M. Santarelli, and M. Cali, International Journal of Hydrogen Energy, 34(3), 1143 (2009).

28. J. Zhang, Y. Tang, C. Song, J. Zhang, and H. Wang, Journal of Power Sources, 163(1), 532 (2006).

29. M. Schalenbach, W. Lueke, W. Lehnert, and D. Stolten, Electrochimica Acta., 214, 362 (2016).

30. I. Barin and G. Platzki, Thermochemical data of pure substances, volume 3.ed., 3 edition, Weinheim (1995).

31. M. Schalenbach, M. Carmo, D. L. Fritz, J. Mergel, and D. Stolten, International Journal of Hydrogen Energy, 38(35), 14921 (2013).

32. J. C. F. Boodts and S. Trasatti, Journal of Applied Electrochemistry, 19(2), 255 (1989).

33. J. Divisek, R. Jung, and D. Britz, Journal of Applied Electrochemistry, 20(2), 186 (1990).

34. M. Schalenbach, W. Lueke, and D. Stolten, Journal of The Electrochemical Society, submitted (2016).
35. P. Vermeiren, W. Adriansens, J. Moreels, and R. Leysen, International Journal of Hydrogen Energy, 23(5), 321 (1998).

36. J. Xu, G. Liu, J. Li, and X. Wang, Electrochimica Acta, 59, 105 (2012).

37. G. Schiller, R. Henne, and V. Borck, Journal of Thermal Spray Technology, 4(2), 185 (1995).

38. P. Fouilloux, Applied Catalysis, 8(1), 1 (1983).

39. AGFA, Zirfon Perl UTP 500. Separator membrane for alkaline water eelctrolysis. Product information. (2016).

40. D. Pletcher and X. Li, International Journal of Hydrogen Energy, 36(23), 15089 (2011).

41. R. Gilliam, J. Graydon, D. Kirk, and S. Thorpe, International Journal of Hydrogen Energy, 32(3), 359 (2007).

42. DuPont Fuel Cells, DuPont Nafion PFSA Membranes, http://www2.dupont.com/ FuelCells/en_US/products/nafion.html (2015).

43. Johnson Matthey Fuel Cells, http://www.jmfuelcells.com/products/fuel_cell_catalysts, p. 1 (2015).

44. S. Litster and G. McLean, Journal of Power Sources, 130(1-2), 61 (2004).

45. L. Trotochaud, S. L. Young, J. K. Ranney, and S. W. Boettcher, Journal of the American Chemical Society, 136(18), 6744 (2014).

46. T. Dickinson, A. F Povey, and P. M. A. Sherwood, J. Chem., 73, 327 (1977).

47. J. O. Bockris, a. K. N. Reddy, and B. Rao, Journal of The Electrochemical Society, 113(11), 1133 (1966).

48. A. Kowal, R. Niewiara, B. Peroczyk, and J. Haber, Langmuir, 12(5), 2332 (1996).

49. M. Schalenbach, M. Zillgitt, W. Maier, and D. Stolten, ACS applied materials \& interfaces, 7(29), 15746 (2015).

50. W. Ryden and A. Lawson, Physics Letters, 26A(5), 209 (1968).

51. C. Boyer, S. Gamburzev, O. Velev, S. Srinivasan, and A. J. Appleby, Electrochim Acta, 43(24), 3703 (1998).

52. Y.-H. Fang and Z.-P. Liu, JACS, 132(51), 18214 (2010)

53. M. Schalenbach, M. Hoeh, J. Gostick, W. Lueke, and D. Stolten, Physical Chemistry $C, \mathbf{1 1 9}(45), 25156$ (2015).

54. M. Schalenbach, T. Hoefner, P. Paciok, M. Carmo, W. Lueke, and D. Stolten, Physical Chemistry C, 119(45), 25145 (2015).

55. C. Ziegler, S. Thiele, and R. Zengerle, Journal of Power Sources, 196(4), 2094 (2011).

56. W. K. Epting, J. Gelb, and S. Litster, Materials Views, 22(3), 555 (2012).

57. W. J. Hamer, W. Jay, and H. J. DeWane, Electrolytic conductance and the conductances of the halogen acids in water. No. 33. US National Bureau of Standards, (1970).

58. K. E. Gubbins and R. D. J. Walker, Journal of The Electrochemical Society, 112(5), 469 (1965).

59. P. Ruetschi and R. F. Amlie, The Journal of Physical Chemistry, 622(6), 718 (1966).

60. E. Narita, F. Lawson, and K. N. Han, Hydrometallurgy, 10(1), 21 (1983).

61. P. Ruetschi and R. F. Amlie, The Journal of Physical Chemistry, 70(8), 718 (1966).

62. R. E. Davis, G. L. Horvath, and C. W. Tobias, Electrochimica Acta, 12(3), 287 (1967).

63. J. R. Varcoe, P. Atanassov, D. R. Dekel, A. M. Herring, M. A. Hickner, P. A. Kohl, A. R. Kucernak, W. E. Mustain, K. Nijmeijer, K. Scott, T. Xu, and L. Zhuang, Energy Environ. Sci., 7, 3135 (2014).

64. J. B. Gerken, S. E. Shaner, R. C. Massé, N. J Porubsky, and S. S. Stahl, Energy Environ. Sci., 7(7), 2376 (2014).

65. I. C. Man, H.-Y. Su, F. Calle-Vallejo, H. A. Hansen, J. I. Martínez, N. G. Inoglu, J. Kitchin, T. F. Jaramillo, J. K. Nørskov, and J. Rossmeisl, ChemCatChem, 3(7), 1159 (2011).

66. W. Hong, M. Risch, K. A. Stoerzinger, A. J. L. Grimaud, J. Suntivich, and Y. Shao-Horn, Energy Environ. Sci., 8, 1404 (2015).

67. D. Chen, C. Chen, Z. M. Baiyee, Z. Shao, and F. Ciucci, Chemical reviews, 115(18), 9869 (2015)

68. L. Birry and A. Lasia, Journal of Applied Electrochemistry, 34(7), 735 (2004)

69. D. E. Hall, Journal of The Electrochemical Society, 132(2), 41C (1985).

70. I. Herraiz-Cardona, E. Ortega, L. Vazquez-Gomez, and V. Perez-Herranz, International Journal of Hydrogen Energy, 37(3), 2147 (2012).

71. V. Ganesh and V. Lakshminarayanan, Electrochimica Acta, 49(21), 3561 (2004).

72. J. S. Chen, J. Ren, M. Shalom, T. Fellinger, and M. Antonietti, ACS Applied Materials and Interfaces, 8(8), 5509 (2016)

73. N. Danilovic, R. Subbaraman, K.-C. Chang, S. H. Chang, Y. J. Kang, J. Snyder, A. P. Paulikas, D. Strmcnik, Y.-T. Kim, D. Myers, V. R Stamenkovic, and N. M. Markovic, The Journal of Physical Chemistry Letters, 5(14), 2474 (2014).

74. S. Cherevko, A. R. Zeradjanin, A. A. Topalov, N. Kulyk, I. Katsounaros, and K. J. J. Mayrhofer, ChemCatChem, 6(8), 2219 (2014).

75. C. Baldizzone, L. Gan, N. Hodnik, G. P. Keeley, A. Kostka, M. Heggen, P. Strasser, and K. J. J. Mayrhofer, ACS Catalysis, 5(9), 5000 (2015).

76. H. Janssen, J. Bringmann, B. Emonts, and V. Schroeder, International Journal of Hydrogen Energy, 29(7), 759 (2004) 